University of Windsor

Scholarship at UWindsor

2012

\title{
Microarray-based identification of Pitx3 targets during Xenopus embryogenesis
}

L Hooker

C Smoczer

Farhad Khosrowshahian

University of Windsor

Michael J. Crawford

University of Windsor

Follow this and additional works at: https://scholar.uwindsor.ca/biologypub

Part of the Biology Commons

\section{Recommended Citation}

Hooker, L; Smoczer, C; Khosrowshahian, Farhad; and Crawford, Michael J., "Microarray-based identification of Pitx3 targets during Xenopus embryogenesis" (2012). Developmental Dynamics, 241, 9, 1487-1505.

https://scholar.uwindsor.ca/biologypub/1

This Article is brought to you for free and open access by the Department of Biological Sciences at Scholarship at UWindsor. It has been accepted for inclusion in Biological Sciences Publications by an authorized administrator of Scholarship at UWindsor. For more information, please contact scholarship@uwindsor.ca. 


\title{
Microarray-Based Identification of Pitx3 Targets During Xenopus Embryogenesis
}

\author{
Lara Hooker, Cristine Smoczer, Farhad KhosrowShahian, Marian Wolanski, \\ and Michael J. Crawford*
}

Background: Unexpected phenotypes resulting from morpholino-mediated translational knockdown of Pitx3 in Xenopus laevis required further investigation regarding the genetic networks in which the gene might play a role. Microarray analysis was, therefore, used to assess global transcriptional changes downstream of Pitx3. Results: From the large data set generated, selected candidate genes were confirmed by reverse transcriptase-polymerase chain reaction (RT-PCR) and in situ hybridization. Conclusions: We have identified four genes as likely direct targets of Pitx3 action: Pax6, $\beta$ Crystallin-b1 (Crybb1), Hes7.1, and Hes4. Four others show equivocal promise worthy of consideration: Vent2, and Ripply2 (aka Ledgerline or Stripy), eFGF and RXR $\alpha$. We also describe the expression pattern of additional and novel genes that are Pitx3-sensitive but that are unlikely to be direct targets. Developmental Dynamics 241:1487-1505, 2012. $\odot 212$ Wiley Periodicals, Inc.

Key words: microarray; Pitx3; morpholino; Xenopus laevis; eye; lens; somite; Pax6; segmentation clock; retinoid; mutant

\section{Key findings:}

- A microarray assay and secondary confirmation of Pitx3 morphants indicates that Pax6, $\boldsymbol{\beta}$ Crystallin-b1 (Crybb1), Hes7.1, and Hes4 are good candidates for direct targets.

- Four other genes show equivocal promise worthy of consideration: Vent2, and Ripply2 (aka Ledgerline or Stripy), $e F G F$ and $R X R \boldsymbol{\alpha}$.

- Novel genes described (but that are likely indirectly affected) are described: Rbp4l, Galectin IX, Baz2b, and Rdh16.

- In addition to previously described interactions in lens and brain, Pitx3 also intersects the segmentation pathway and retinoid regulation.

Accepted 9 July 2012

\section{INTRODUCTION}

Pitx3 encodes a bicoid-like transcription factor that is characterized by a lysine residue at position 50 of the homeodomain. The aphakia (ak) mouse represents a natural Pitx3 mutant model that is the result of two deletions in its regulatory region that abolish eye and brain expression, but leave muscle expression intact (Semina et al., 2000; Rieger et al., 2001; Coulon et al., 2007). This genotype displays microphthalmic eyes that lack developed lenses. They also display impaired differentiation of dopaminergic neurons in the substantia nigra: mutants mimic the symptoms of Parkinson's disease (PD; Varnum and Stevens, 1968; van den Munckhof et al., 2003). In humans, PITX3 disruption can lead to congenital cataracts, anterior segment mesenchymal dysgenesis (ASMD), Peter's anomaly, and/ or microphthalmia (Sakazume et al., 2007). This implicates PITX3 as a major player in the control of gene transcription in lens fibers. In the ventral tegmental area (VTA) and substantia nigra compacta (SNc)

\footnotetext{
Department of Biological Sciences, University of Windsor, Windsor, Ontario, Canada

Grant sponsor: Natural Science and Engineering Research Council of Canada; Grant number: 203459.

* Correspondence to: Michael J. Crawford, Department of Biological Sciences, University of Windsor, 401 Sunset Avenue, Windsor, Ontario, N9B 3P4, Canada. E-mail: mcrawfo@uwindsor.ca

DOI 10.1002/dvdy.23836

Published online 4 August 2012 in Wiley Online Library (wileyonlinelibrary.com).
} 


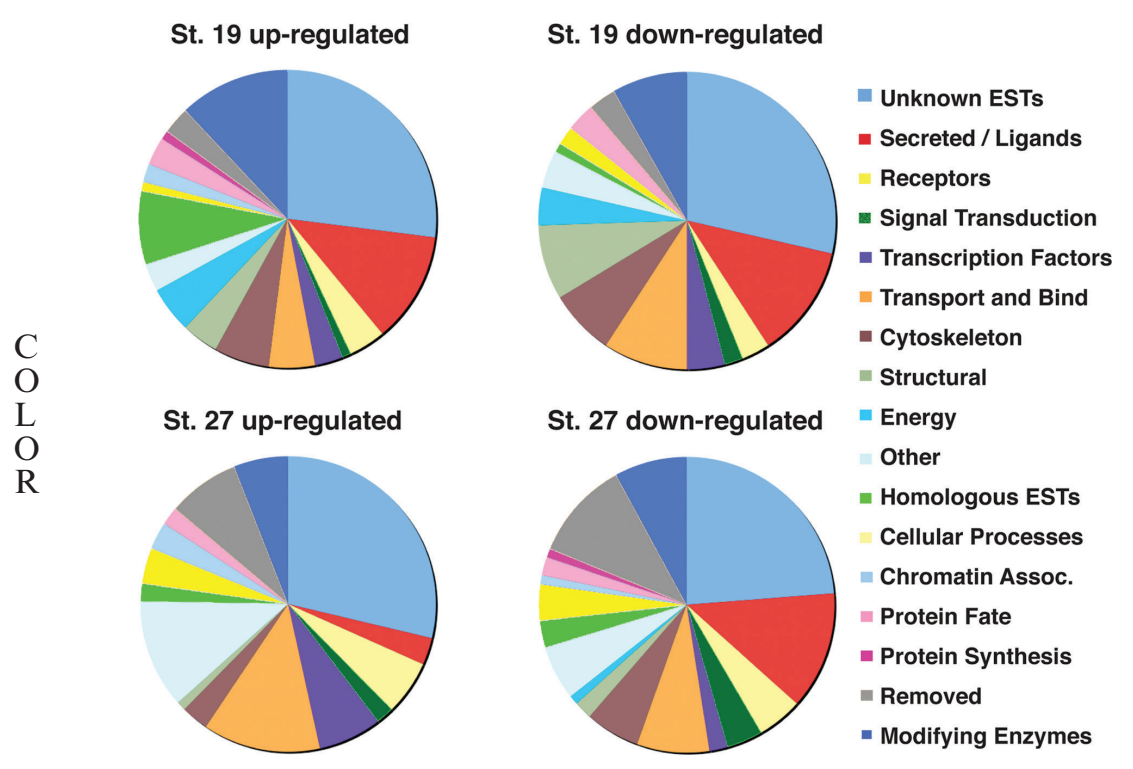

Fig. 1. Microarray data represented according to putative gene function. The 100 most upand down-regulated transcripts affected by Pitx3-morpholino-mediated knockdown were categorized by sequence analysis for stages 19 and 27 of $X$. laevis embryonic development. Colors correspond to functional groups in the legend (right). regions of the midbrain, PITX3 is necessary for the terminal differentiation and survival of mesencephalic dopaminergic neurons (mDA; van den Munckhof et al., 2003; Hwang et al., 2009). Zebrafish pitx3 morphants also exhibit small eyes with lens degeneration, along with misshapen heads, a bent dorsal axis, and reduced jaws and fins (Shi et al., 2005). Disruption of Pitx3 in Xenopus laevis impedes development of lens and retina, and recent evidence suggests an additional role in dorsal axis segmentation and in laterality (Khosrowshahian et al., 2005; Shi et al., 2005; Smoczer et al., In Press). In zebrafish, Pitx3 expresses in the hypoblast of gastrulating embryos (Dutta et al., 2005), and the transcript is detectable by reverse transcriptase-polymerase chain reaction (RT-PCR) in pregastrula Xenopus (Khosrowshahian et al., 2005). These two studies

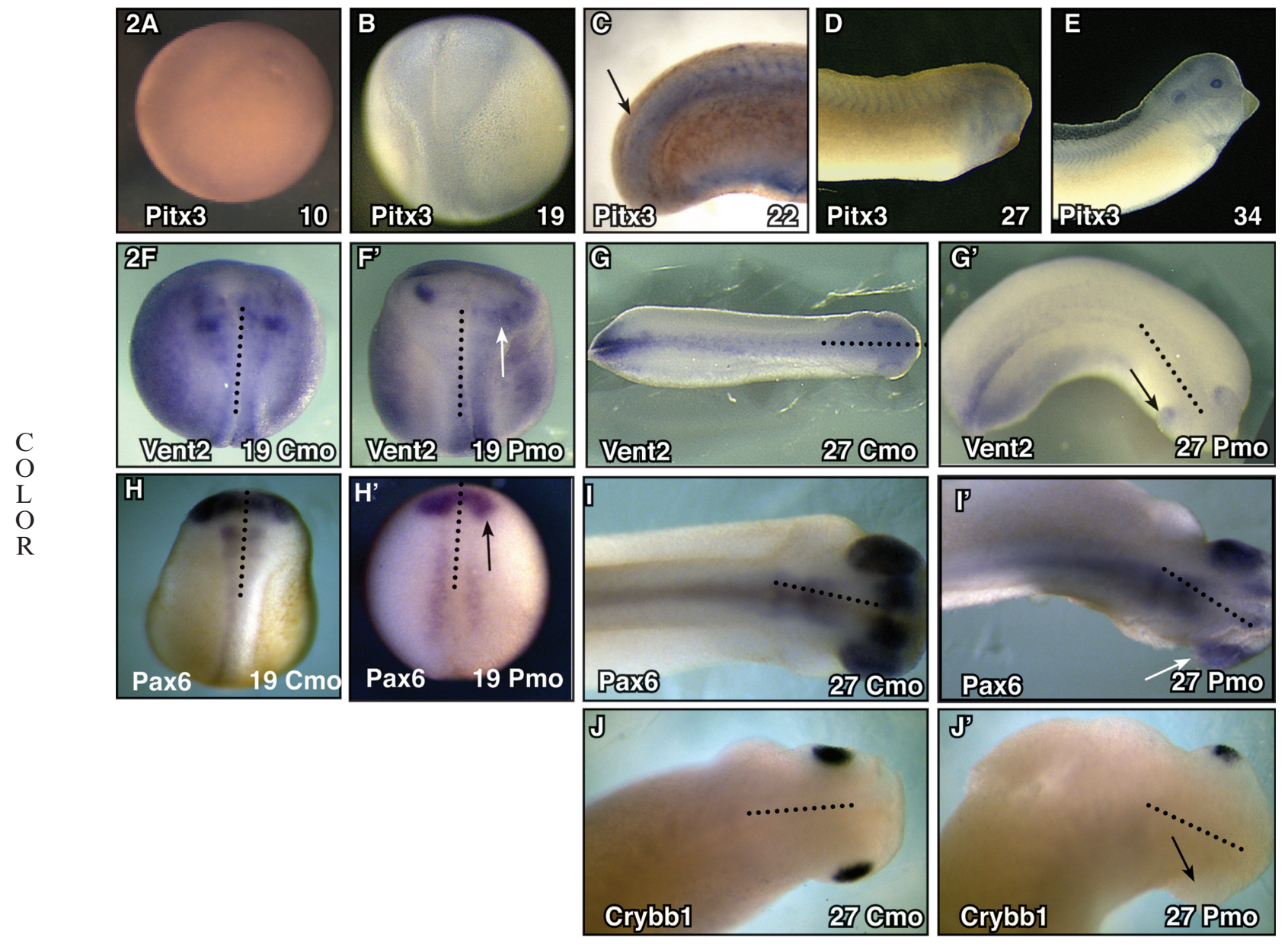

Fig. 2. 
suggest an earlier involvement for the gene in dorso-anterior patterning than is generally understood.

Pitx3 binds target DNA to regulate transcription of downstream genes by means of bicoid binding elements (BBE; TAATCC; Lamonerie et al., 1996; Amendt et al., 1998). Pitx3 directly regulates $M I P / A q u a p o r i n ~ O$, which encodes an abundant protein in the lens that functions as an osmotic regulator and cell adhesion molecule (Chepelinsky, 2009; Huang and He, 2010; Sorokina et al., 2011). In zebrafish, pitx3 acts upstream of the transcription factor foxe3, which is necessary for the transition of lens epithelial cells into differentiated secondary lens fibers by means of nuclear degradation (Shi et al., 2005). Pitx3 is also thought to regulate the balance between mitosis and terminal differentiation in the equatorial region of the lens: here, it operates upstream of cell cycle inhibitors p27Kip1 and p57Kip2 (Ho et al., 2009). Within midbrain regions, it directly regulates tyrosine hydroxylase $(\mathrm{TH})$ expression, the rate-limiting enzyme in dopamine production (Landis et al., 1988; Lebel et al., 2001; Messmer et al., 2007). It also controls the neurotransmission of dopamine in mDA neurons by means of regulation of vesicular monoamine transporter 2 (VMAT2) and dopamine transporter (DAT; Hwang et al., 2009). Direct regulation of Adh2 in $\mathrm{mDA}$ neurons affects the production of retinoic acid that is necessary for proper neuron development (Jacobs et al., 2007). To complicate matters, Pitx3 is a versatile transcription factor: depending upon signaling context, it can act as either a transcriptional ac- tivator or as a repressor (Cazorla et al., 2000; Messmer et al., 2007).

We performed a microarray analysis to compare the transcriptomes of Pitx 3 and control-morphants at stages 19 (when eye development is commencing) and 27 (when lens differentiation begins; Nieuwkoop and Faber, 1967). We elected to use morpholinos because ectopic expression and dominant negative approaches could affect the response elements of other Pitx family members: the ectopic expression approach is impossible to restrict solely to Pitx3 expression domains, and the homeodomain sequences of Pitx2 and 3, for example, are identical. Pitx2 and 3 differ from Pitx1 by a single amino acid in the turn between helices I and II.

Although the preponderance of literature regarding the gene relates to lens and mDA neurons, Pitx3 also expresses broadly throughout gastrulation, and later in somites, and lateral plate mesoderm (Pommereit et al., 2001; Khosrowshahian et al., 2005; Smoczer et al., In Press). In zebrafish, pitx3 expresses in the demarcation of the mesendodermderived polster (Dutta et al., 2005). Ectodermal explants have been useful as source material for Xenopus microarray experiments in the past, but this restriction to a single germinal layer would miss some likely Pitx3 targets, and in addition would require the complicating necessity of neural inducing agents. That said, the interpretation of results can also be confounded by the feature that morpholino-mediated translational knockdown, unlike RNAi approaches, solely affects translation and does not appear to affect mRNA degradation rates. Indeed, some

Fig. 2. In situ hybridization analysis for putative targets of Pitx3 involved in eye development. Visual comparisons of gene expression patterns between right-side injected control-morpholino (Cmo) or Pitx3-morpholino (Pmo) embryos and their untreated contralateral control. A-E: Pitx3 expression patterns are presented for comparison (adapted from Khosrowshahian et al., 2005; Smoczer et al., In Press). A: demonstrates faint but detectable signal throughout the ectoderm and in agreement with reverse transcriptase-polymerase chain reaction (RT-PCR) results. B: Expression is detectable throughout neural ridge, while at stage 22 , the gene is expressed in a cleared specimen where an arrow indicates presomitic mesoderm. By stage 27 (D), Pitx3 is detectable throughout much of the head ectoderm, as well as in branchial arches and somites. This pattern restricts later to somites, otic vesicle, lens, and brain (D). F-G': Vent2 expression is reduced in the developing eye field at stage 19 for the Pitx3-morpholino (Pmo) injected side $\left(A^{\prime}\right.$ white arrow) and at stage 27 ( $B^{\prime}$ black arrow), when compared with control-morpholino $(\mathrm{Cmo})$ injected embryos $(A, B) . H_{-} I^{\prime}$ : Pax6 shows reduced expression in eye field on Pmo side of embryos at stage 19 ( $C^{\prime}$ black arrow) and 27 (D' white arrow). $\mathbf{J}-\mathbf{J}^{\prime}$ : Crybb1 shows drastic loss of expression in the eye vesicle on the Pmo-treated side of stage 27 embryo $\left(E^{\prime}\right)$ and no difference caused by $C$ mo treatment $(E)$. Dotted line represents the midline of the embryo, separating injected right side from contralateral left side control.

embryos are suspected to compensate for morpholino-mediated knockdown by releasing more transcript into circulation (Eisen and Smith, 2008).

We designed our search for Pitx 3 targets to be as broad as possible, and consequently we sampled from whole embryos. The results generated a long list of genes that are affected by Pitx3 mis-regulation. We characterized novel transcripts that represent putative targets of Pitx3 and report plausible genetic pathways that are regulated by this multifaceted transcription factor.

\section{RESULTS AND DISCUSSION Microarray Analysis}

Morpholino specificity has been previously published and reported to selectively reduce Pitx3 transcript and protein levels, with the control-morpholino having none of these effects (Khosrowshahian et al., 2005). This specificity has subsequently been confirmed using a second Pitx3 morpholino and missense control (Smoczer et al., In Press). Xenopus microarray GeneChips (Affymetrix) were used, and the data were analyzed comparing control-morpholino treatments to Pitx3-morpholino treatments. The threshold for consideration was set at a two-fold cutoff with a $P$ value of $<0.05$. We categorized the top 100 up- and down-regulated transcripts at each stage, with regard to function, and generated pie charts to show their distribution (Fig. 1).

Among gene categories, the largest group affected consists of transcripts with unknown function (expressed sequence tags; ESTs). Other transcripts encoded secreted factors and ligands, transport and binding proteins, and modifying enzymes. In summary, changes in expression profiles for these genes implicate Pitx3 in some of the indirect controls upon morphogenesis such as those exerting an effect by means of regulation of secreted morphogens.

When assessed in broad strokes, the secreted factors and ligands are notably less up-regulated in morphants at stage 27 than at stage 19 ; however, by contrast, transcription factors are more up-regulated at stage 27. At stage 19, structural proteins were more profoundly affected (both up- or down-regulated) as a consequence of 


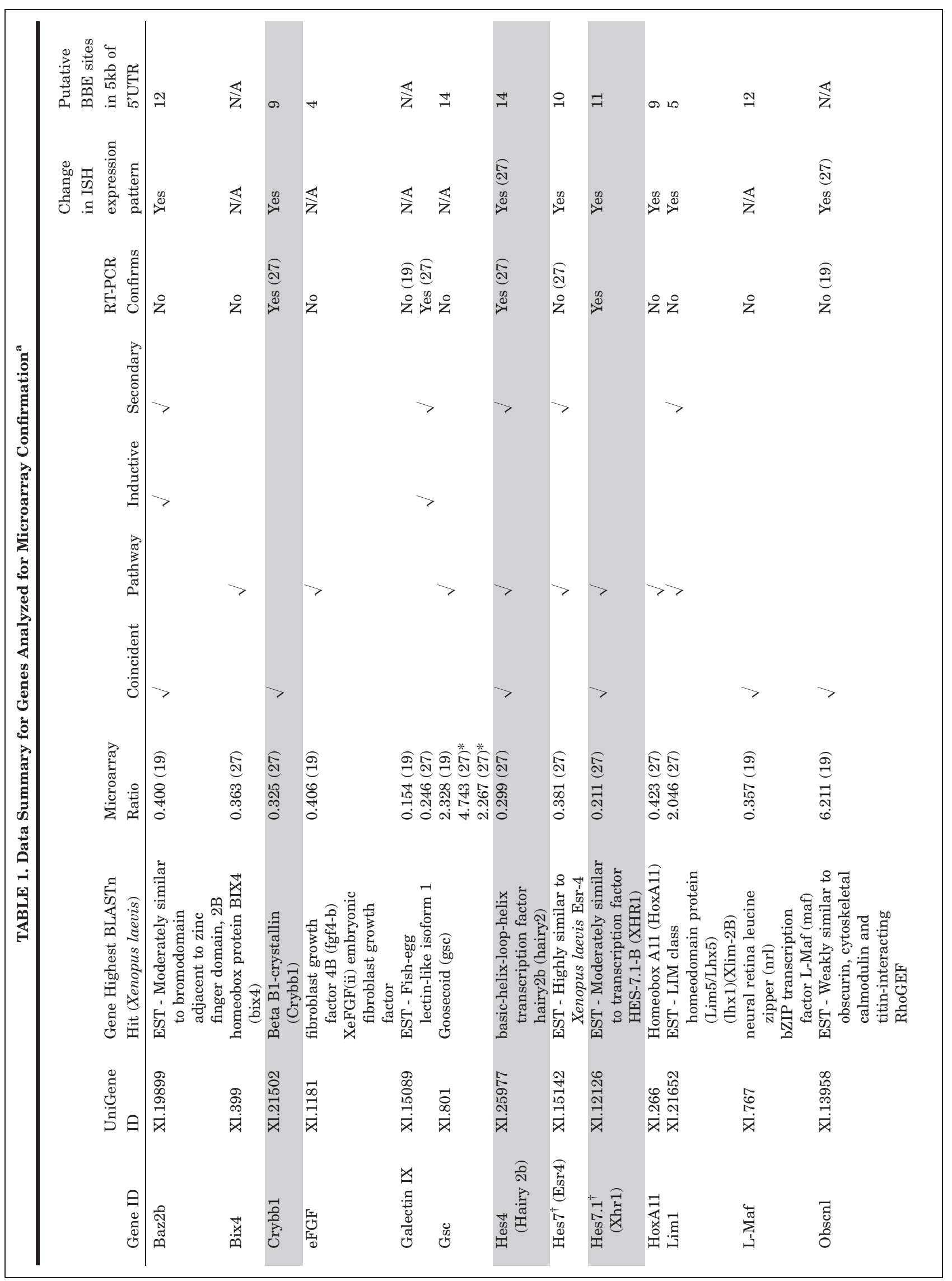




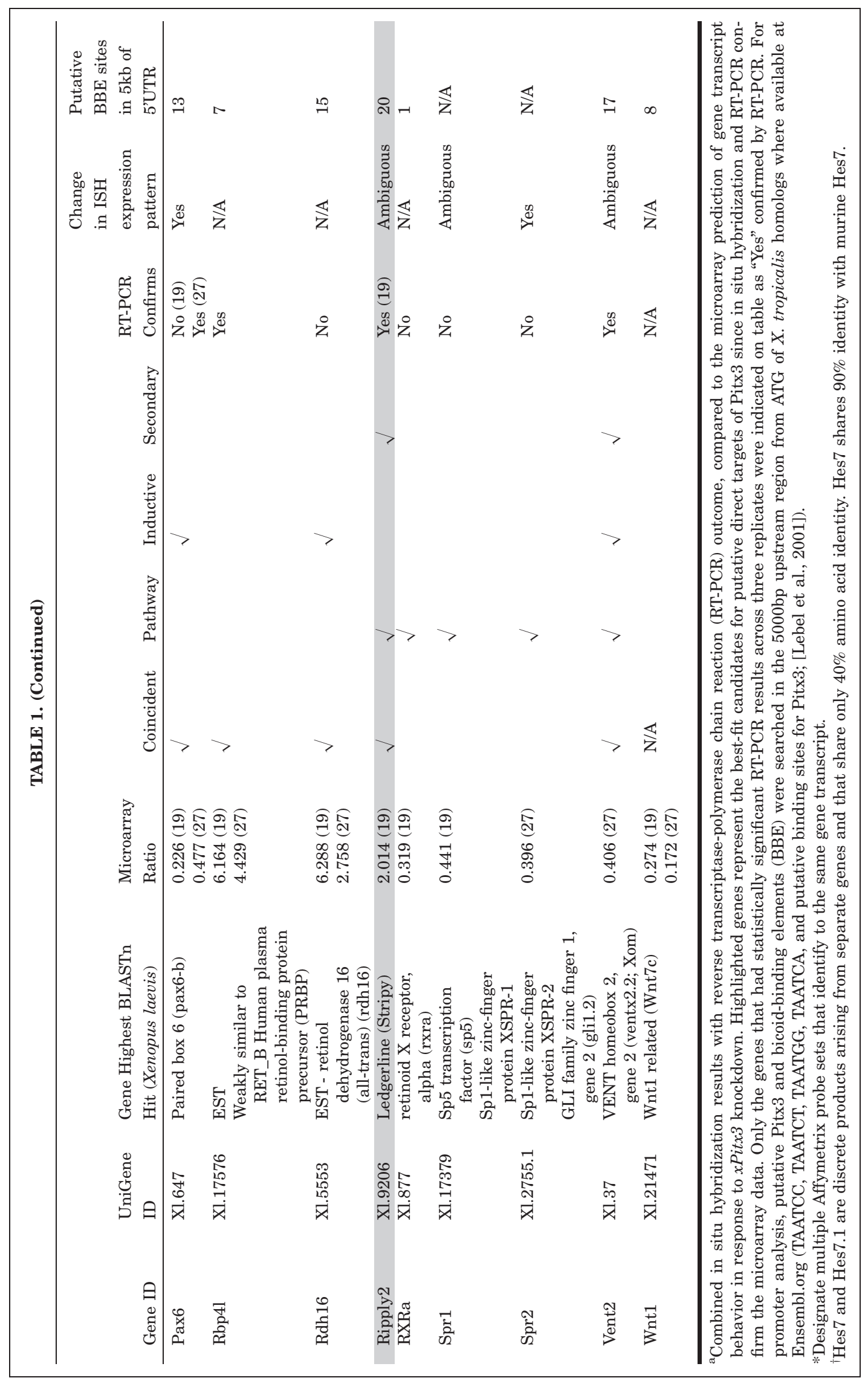




\begin{tabular}{llll}
\multicolumn{1}{l}{ TABLE 2. Additional Genes Identified in the Microarray Data That Pertain to Genetic Pathways Implicated in this } \\
Study
\end{tabular}

Pitx3 knockdown than at stage 27. A similar picture developed for signal transduction. The disruptions are consistent with embryos experiencing impaired movement, signaling and morphological changes during neurulation at stage 19, when the body plan is arguably at its most ductile phase. Overall, chromatin modifying genes were up-regulated more than downregulated at both stages.

Our aim was to use the microarray experiments to deduce novel Pitx3 pathways, so we first focused upon the transcripts that were most upand down-regulated in response to morpholino-mediated knockdown of Pitx3. In published studies involving samples from rapidly developing systems, microarray and RT-PCR results have occasionally been at odds. Moreover, microarrays are likely to be sensitive to subtle differences in the staging of developmental samples: quantitative data might not be fairly interpreted in absolute terms. We elected to categorize on the basis of trend: if gene expression levels were altered two-fold or more relative to controls, and this was repeated in a second experiment, we pursued the gene for further analysis using semiquantitative RT-PCR analysis and riboprobe in situ hybridization. Genes that expressed in expression patterns that overlapped with Pitx3 were deemed possible direct target genes of Pitx3. Of this subset, we focused upon those that also possessed putative Pitx3 binding motifs in the $5^{\prime}$ untranslated region (UTR) of $X$. tropicalis sequences. These were used for the reason that they were uniformly available, and all of the Xenopus laevis ESTs and genes that we have examined to date enjoy near perfect homology (Table 1). We then looked deeper into the data set to see if genes in the same signaling pathway or developmental process were similarly affected (Table 2). If the behaviors of the expanded set grouped in a logical manner, and if the behaviors were consistent with the Pitx3 knockdown phenotypes, these genes were further analyzed by RT-PCR or in situ hybridization.

The affected genes can be classified as: potential direct targets of Pitx3; genes that operate within a Pitx3 regulated pathway; or genes that are affected indirectly and outside of the domain of Pitx3 expression as a result of grossly perturbed patterns of organ differentiation. Only four genes with putative Pitx3 binding motifs displayed both RT-PCR and riboprobe in situ hybridization pat- terns that were unequivocally consistent with the microarray trend: Pax6, $\beta$ b1Crystallin (Crybb1), Hes7.1, and Hes4. Two others, Vent2, and Ripply2 (aka Ledgerline or Stripy) displayed altered in situ hybridization patterns that were difficult to interpret with respect to expression level, because their respective patterns were affected differently in disparate domains (Table 1). For example, although Vent2 expression is obliterated in the optic region consistent with the microarray trend, the gene is up-regulated in the posterior endoderm. Similarly, the banded pattern of Ripply2 expression is anteriorized and delayed by morpholino at early stages, but appears to recover to some extent by stage 27 .

In $X$. laevis, Pitx3 expresses in the developing lens, the otic vesicle, and head mesenchyme, as well as in the branchial arches and along the anteroposterior axis in the developing somites (Pommereit et al., 2001; Khosrowshahian et al., 2005). Insofar as Pitx3 is critical to lens placode function, it plays a critical role in frog retina induction (Khosrowshahian et al., 2005), so one might expect gene expression in retina to be indirectly affected as well. Eye pathway genes Pax6, L-Maf, and Crybb1, express in 

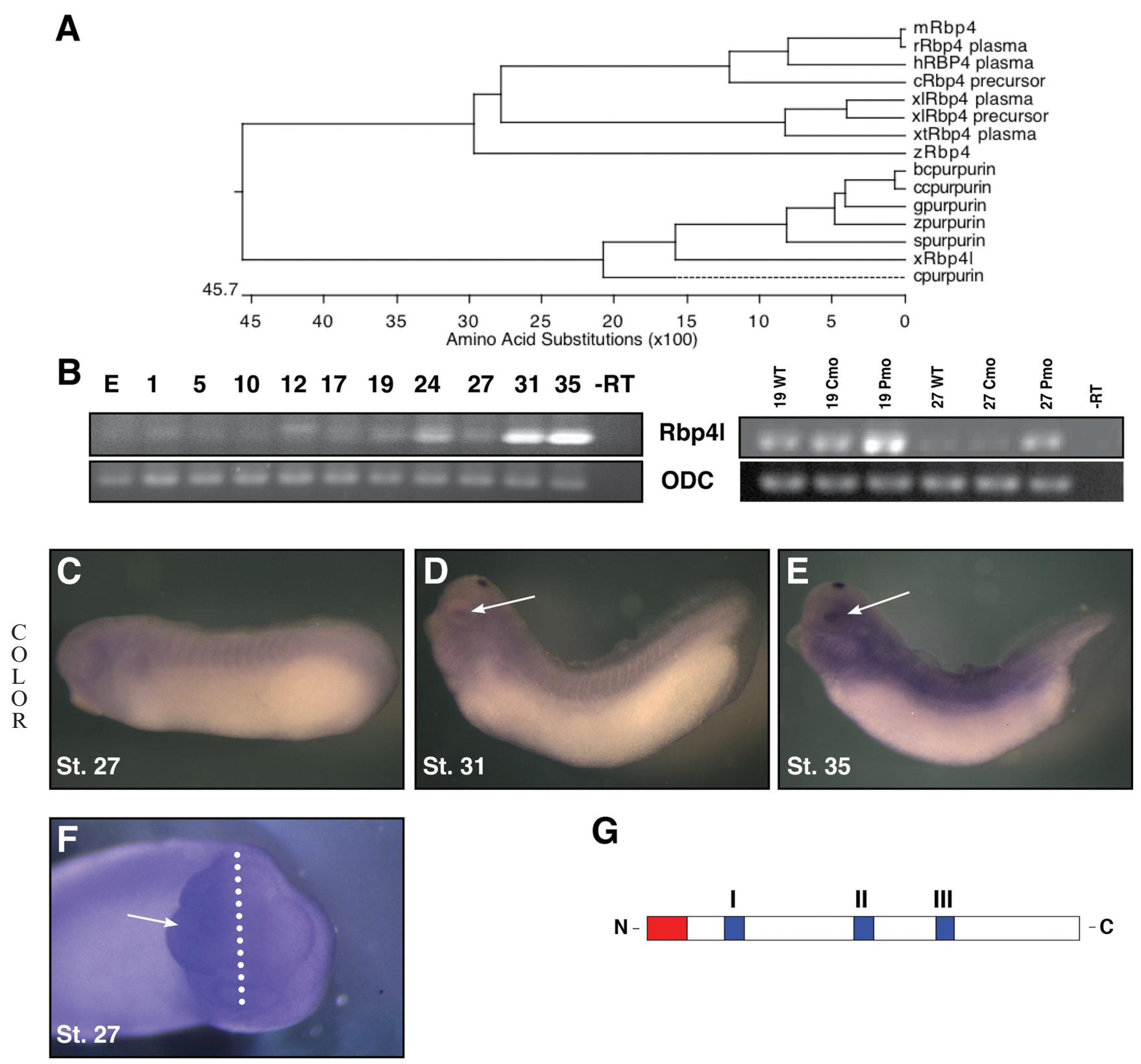

G

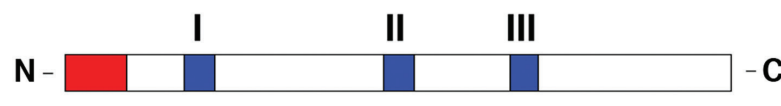

Fig. 3. Characterization of a novel transcript, $R b p 4 l$, in $X$. laevis. A: Protein alignment showing distinct groups between retinol binding proteins and purpurin family members. B: Temporal expression of Rbp4l throughout embryonic stages of development, showing slight detection at stages 17 and 24, and an increase in expression at stages 31 and 35. Confirmation of microarray predictions by means of reverse transcriptase-polymerase chain reaction (RT-PCR), showing an increase in Rbp4l expression in response to Pitx3-morpholino (Pmo) at stages 19 and 27 , when compared with wild-type (WT) and control-morpholino (Cmo) treatments. C-E: In situ hybridization with antisense riboprobe against Rbp4l transcript shows expression at stages 27 (C), 31 (D), and 35 (E) concentrated in the developing lens (white arrows, D and E) and at the dorsal midline of the developing midbrain region. F: An embryo injected unilaterally with Pitx3 morpholino on its right side (left of the dotted line) displayed enhanced and general expression in the craniofacial region. G: A schematic diagram of Rbp4l protein depicting a secretory signal at the $\mathrm{N}$-terminus (red) and three characteristic lipocalin motifs (blue) that classify this protein as a member of the kernel subfamily of lipocalins. GenBank accession numbers used to generate phylogenetic tree (A) are as follows: xRbp4l CD362061 (X. laevis), rRbp4 plasma BC167099 (rat), mRbp4 BC031809 (mouse), hRBP4 plasma AL356214 (human), cRbp4 precursor NM_205238 (chick), xIRbp4 precursor NM_001087726 (X. laevis), xIRb4 plasma NM_001086998 (X. laevis), xtRbp4 plasma NM_001015748 (X. tropicalis), zRbp4 NM_130920 (zebrafish), zpurpurin AB242211 (zebrafish), spurpurin NP_001135080 (salmon), ccpurpurin NP_001187969 (channel catfish), gpurpurin BAD42450 (goldfish), bcpurpurin AD028302 (blue catfish), cpurpurin P08938 (chick).

the developing lens, and thus are good candidates for Pitx3 targets. Vent2, Rbp4l (purpurin), Galectin IX, and $\operatorname{Rax} 1$ express in early retina, and are all affected in morphants. They likely represent examples of the indirect consequences of Pitx3 perturbation. Moreover, a microarray survey of
Aphakia mice revealed a link between Pitx3 perturbation and regulation of Pax6 and Rbp4 (Münster, 2005). All of the aforementioned 
A

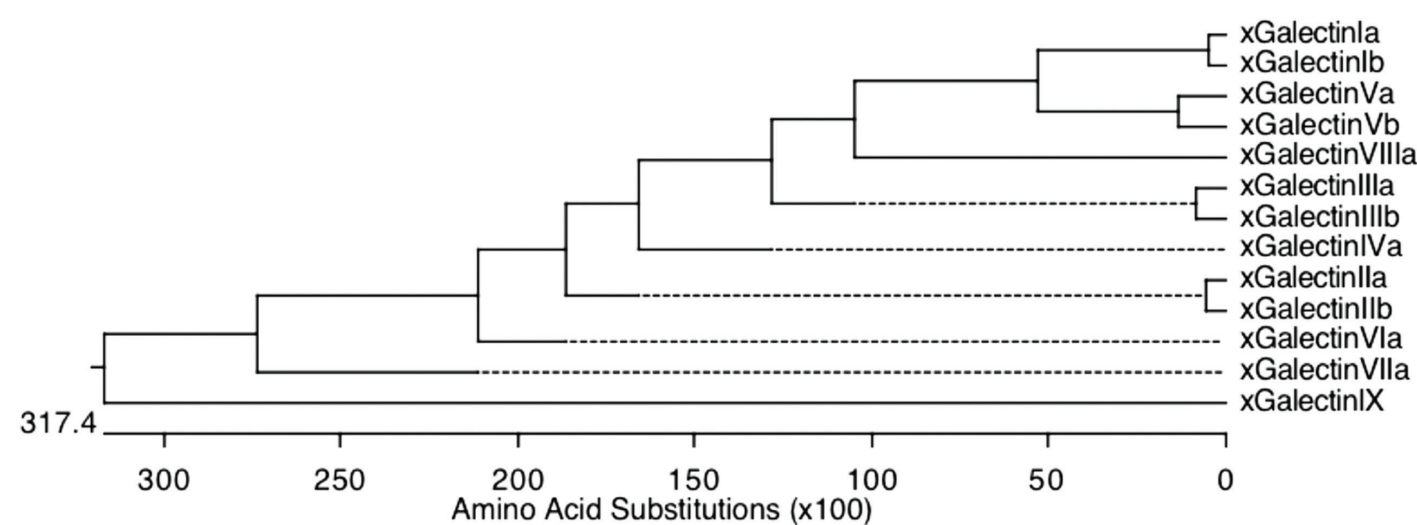

$\begin{array}{ll}\text { C } & \text { B }\end{array}$

$\mathrm{L}$

$\mathrm{O}$

$\begin{array}{llllllllllll}\text { E } & 1 & 5 & 10 & 12 & 17 & 19 & 24 & 27 & 31 & 35 & \text {-RT }\end{array}$
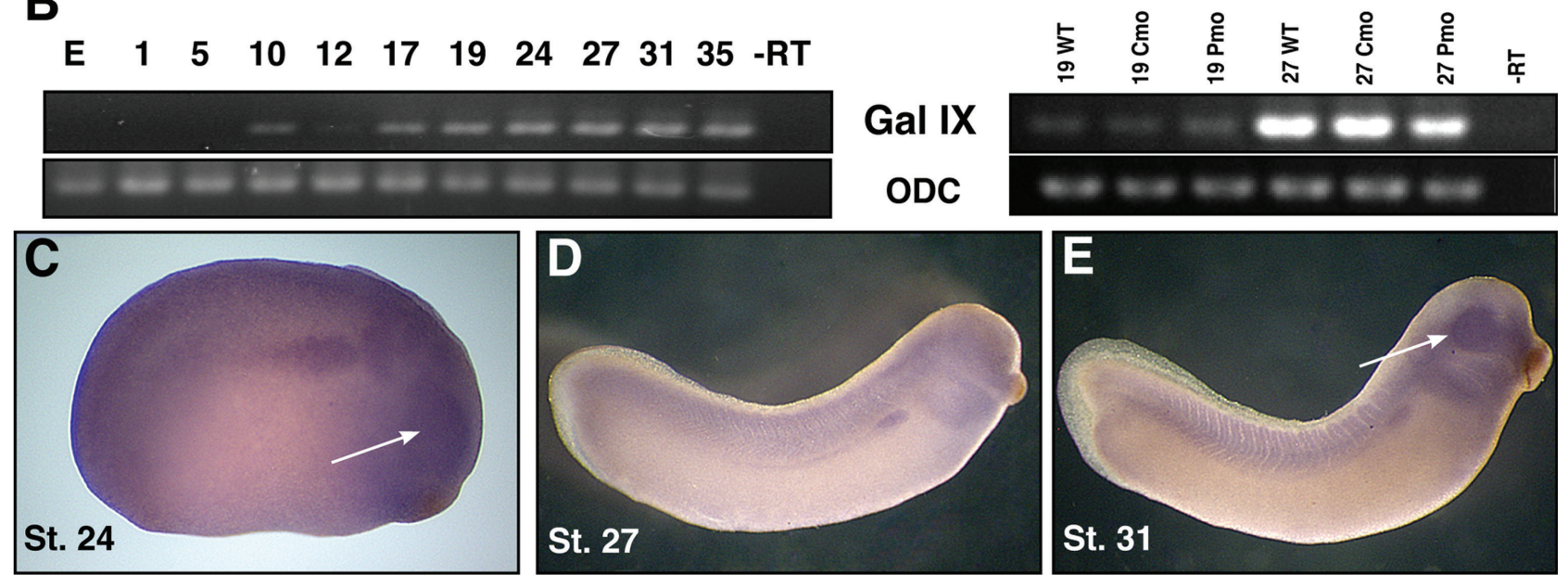

Fig. 4.

A
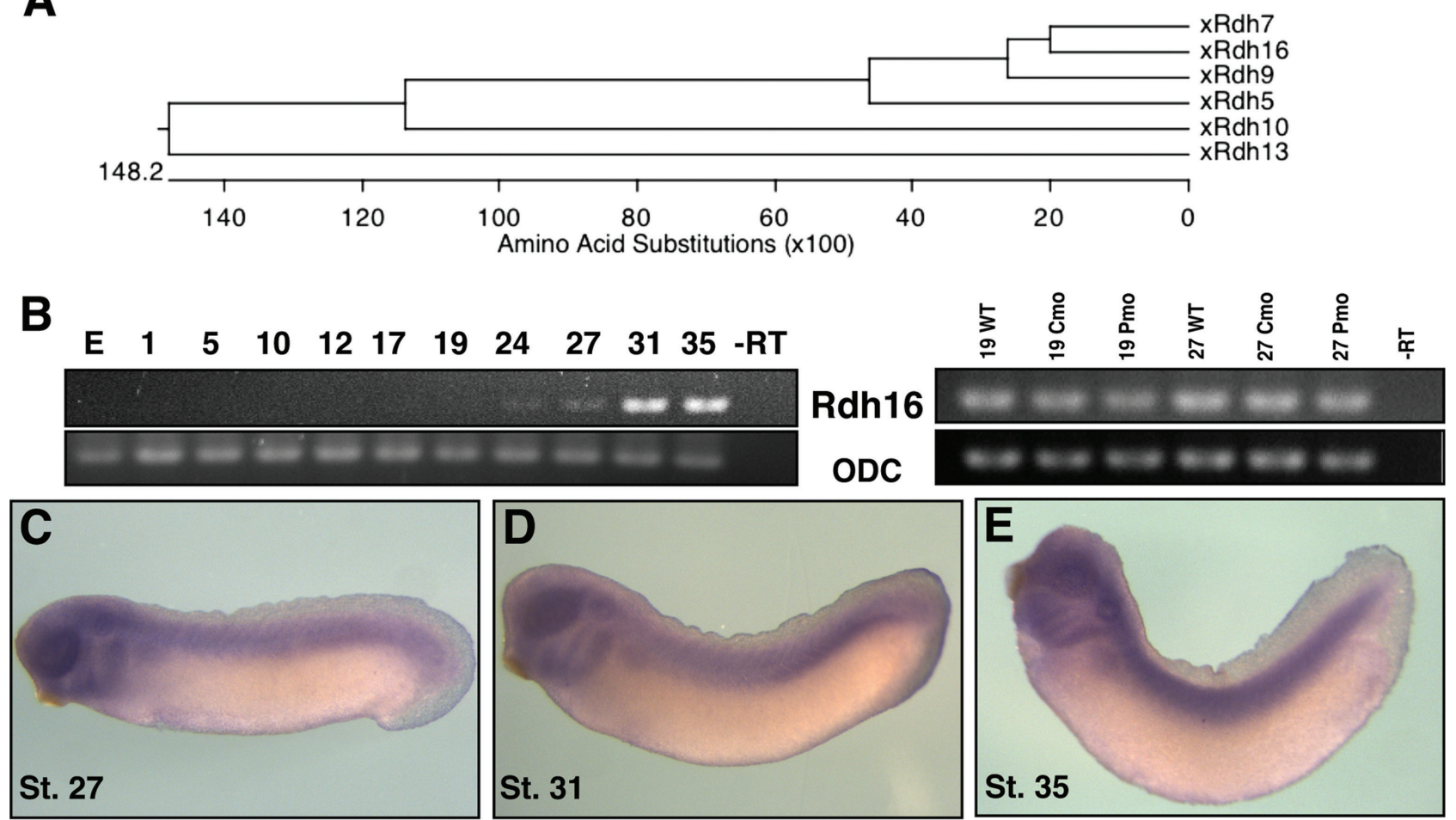

Fig. 5. 
provide validation for the efficacy of the microarray. Unfortunately, none of the previously published and characterized targets of Pitx3 are represented on the microarray; however, one of the probe sets is to an EST that has homology to MIP/Aquaporin $O$, and it is down-regulated consistent with expectation.

\section{Riboprobe In Situ Hybridization}

We assessed the effect of Pitx3 perturbation by injecting embryos at the two-cell stage such that the left and right sides of the developing embryo could be compared as embryogenesis ensued: morphant phenotypes were monitored on the "mutant" side relative to the contralateral control. Candidate gene expression patterns F2 F3 were assessed for perturbation in F4 F5 morphants and for a role in develF6 F7 oping eye (Figs. 2-7), brain (Fig. 8), F8 F9 somite (Fig. 9), and tailbud F10 (Fig. 10).

\section{Eye development.}

Among other domains, Vent2 (a.k.a. Ventx2) is expressed in the dorsal retina (Fig. 2F,G) and it shows structural and functional homology to two Dro- sophila proteins, Om1D and BarH1, which are necessary for the differentiation of photoreceptor cells in the eye (Ladher et al., 1996). Along with Vent2, Pax6, and Crybb1 are perturbed in Pitx3 morphants (Fig. 2H-J).

Pax6 is required and sufficient for the initiation of eye development where it specifies the lens and retinal primordia (Halder et al., 1995), and it too is perturbed in our assays. The microarray and RT-PCR data regarding L-Maf's response to Pitx3 perturbation was ambiguous but is nevertheless worth following up: its relationship to Pitx3 has not been directly assessed; however, Maf binding sites are deleted in the promoter of a naturally occurring mouse Pitx3 mutant (Semina et al., 2000) and $L-M a f$ itself appears to reciprocally possesses 12 putative Pitx3 binding motifs in its $5^{\prime}$-UTR. $L-M a f$ is expressed in the developing lens in response to inductive events from the optic vesicle, and it is directly targeted by Pax6 in chicks (Reza et al., 2002). Maf acts specifically in the lens fiber cells, where it can induce the expression of structural proteins such as the $y$ - and $\beta$ b1-crystallins (Crybb1; Ishibashi and Yasuda, 2001; Cui et al., 2004). Given the presence of numerous potential Pitx3 binding sites in the Crybb1 promoter, and the response of this gene

Fig. 4. Characterization of a novel transcript Galectin $I X$ in $X$. laevis. A: Protein alignment showing amino acid similarities between Xenopus Galectin family members. B: Temporal expression of Galectin IX throughout embryonic stages of development, shows expression beginning at gastrulation (stage 10), decreasing at stage 12, and expressing consistently at stages 17 through 35. Confirmation of microarray predictions by means of reverse transcriptase-polymerase chain reaction (RT-PCR), detect an increase in expression at stage 19 and a decrease at stage 27 for Pitx3-morpholino (Pmo) -treated samples, compared with wild-type (WT) and control-morpholino (Cmo). C-E: Galectin IX transcript expresses at stages 24 (C), 27 (D), and 31 (E) concentrated in the developing eye (white arrows) and presumptive pronephros, persisting in the nephric tubules and ducts. GenBank accession numbers used to generate phylogenetic tree $(A)$ are as follows: xGalectinla AB056478, xGalectinlb AB060969, xGalectinlla AB060970, xGalectinllb AB080016, xGalectinllla AB060971, xGalectinlllb AB080017, xGalectinlVa AB060972, xGalectinVa M88105, xGalectinVb AB080018, xGalectinVla AB080019, xGalectinVIla AB080020, xGalectinVIIla AB080021, xGalectinIX BJ056659.

Fig. 5. Characterization of a novel transcript, $R d h 16$, in X. laevis. A: Protein alignment showing amino acid similarities between Xenopus retinol dehydrogenase ( $\mathrm{rdh}$ ) family members. B: Temporal expression of Rdh16 throughout embryonic stages of development shows faint expression beginning at stage 24 and 27, then increasing at stages 31 and 35 . We were unable to confirm the microarray predictions by means of reverse transcriptase-polymerase chain reaction (RTPCR), as no change in expression was detected between wild-type (WT) control-morpholino (Cmo), or Pitx3-morpholino (Pmo) embryos. C-E: In situ hybridization with antisense riboprobe against Rdh16 transcript, shows expression at stages 27 (C), 31 (D), and 35 (E) concentrated in the eyecup, branchial arches, and otic vesicle, as well as along the lateral plate mesoderm, with a focus on the posterior half (D), and on in the developing myotomes. GenBank accession numbers used to generate phylogenetic tree (A) are as follows: xRdh16 NP_001083356, xRdh7 NP_001079189, xRdh13 NP_001085680, xRdh5 NP_001086194, xRdh9 NP_001090337, xRdh10 ACN32204.

in our Pitx3 morphants, we speculate that Maf and Pitx3 act in tandem to activate the Cry genes. It is worth noting that other Cry genes represented on the microarray also underwent significant fractional change, albeit at less spectacular levels, namely: $\gamma$ crystallin (0.14), $\gamma$ B crystallin (0.3), $\beta$ B3 crystallin (3.8), $\beta$ A3 crystallin (2.74), and species weakly similar to human $\beta B 1$ crystallin (2.12), and $\beta$ B3 crystallin (0.37).

Novel Xenopus retinol-binding
protein Rbp4l is expressed in lens. The microarray indicated that an EST sequence encoding a 197 amino acid protein (GenBank CD362061) was up-regulated at stages 19 and 27 by 6.2 - and 4.4 -fold, respectively. We obtained a clone from NIBB (XL060f11) and after sequencing it, we identified it as a member of the lipocalin protein family, namely RBP4-like (Retinoid binding protein 4 like $-R b p 4 l$ ) or purpurin. These small extracellular proteins characteristically bind hydrophobic molecules and are typically known as transport proteins (Flower, 1996). Figure 3 shows that Rbp4l shares $73 \%$ residue identity with goldfish and salmon, $75 \%$ identity with zebrafish, and 78\% similarity to chick Rbp4l. The similarity to human and murine retinoid-binding protein precursor is on 55 and $54 \%$, respectively. Rbp4l consists of three conserved motifs that create a cupshaped cavity, enabling the protein to bind retinol, and the protein possesses a signal peptide for secretion (Berman et al., 1987). In zebrafish, $r b p 4 l$ is transcribed in photoreceptor cells, and the protein is diffusely detectable in all retinal layers (Tanaka et al., 2007). As a supplier of retinol, a precursor of retinoic acid, this protein activates the retinoic acid and retinoid receptor pathway (RAR and RXR, respectively; Nagy et al., 1996). Rbp4l functions as an extracellular matrix protein in the inter-photoreceptor matrix, and it appears to be necessary for cell adhesion and for the survival of photoreceptor cells in the neural retina (Berman et al., 1987; Nagy et al., 1996). Photoreceptor cells require retinol for phototransduction and retinol is carried to them from the pigmented retinal layer, through the matrix, bound to Rbp4l. In contrast, 


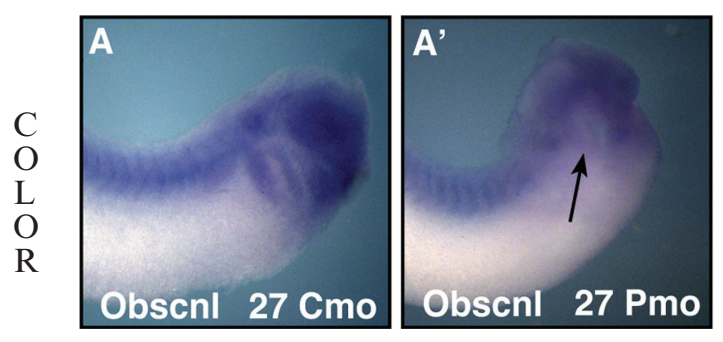

A
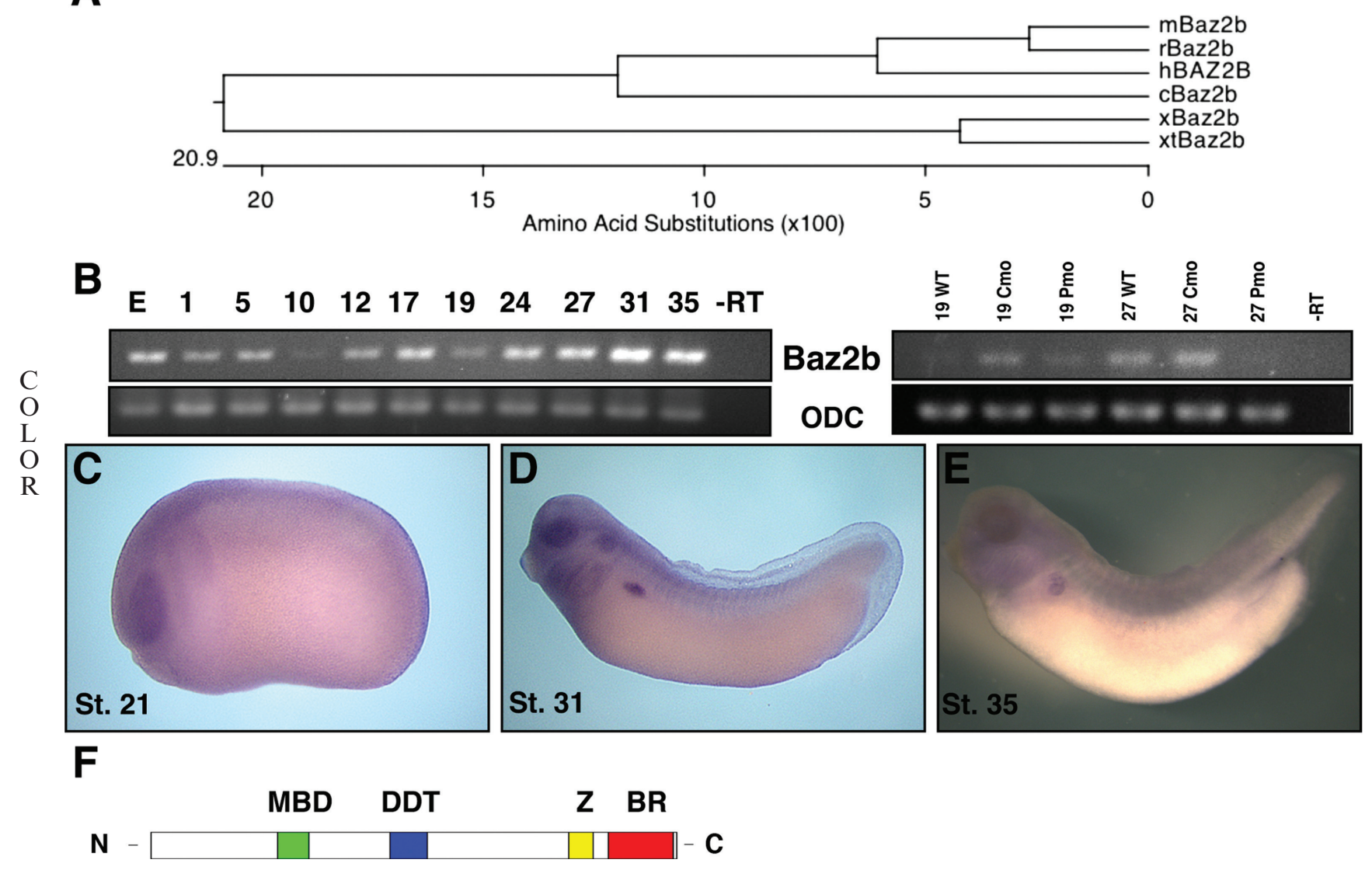

Fig. 7.
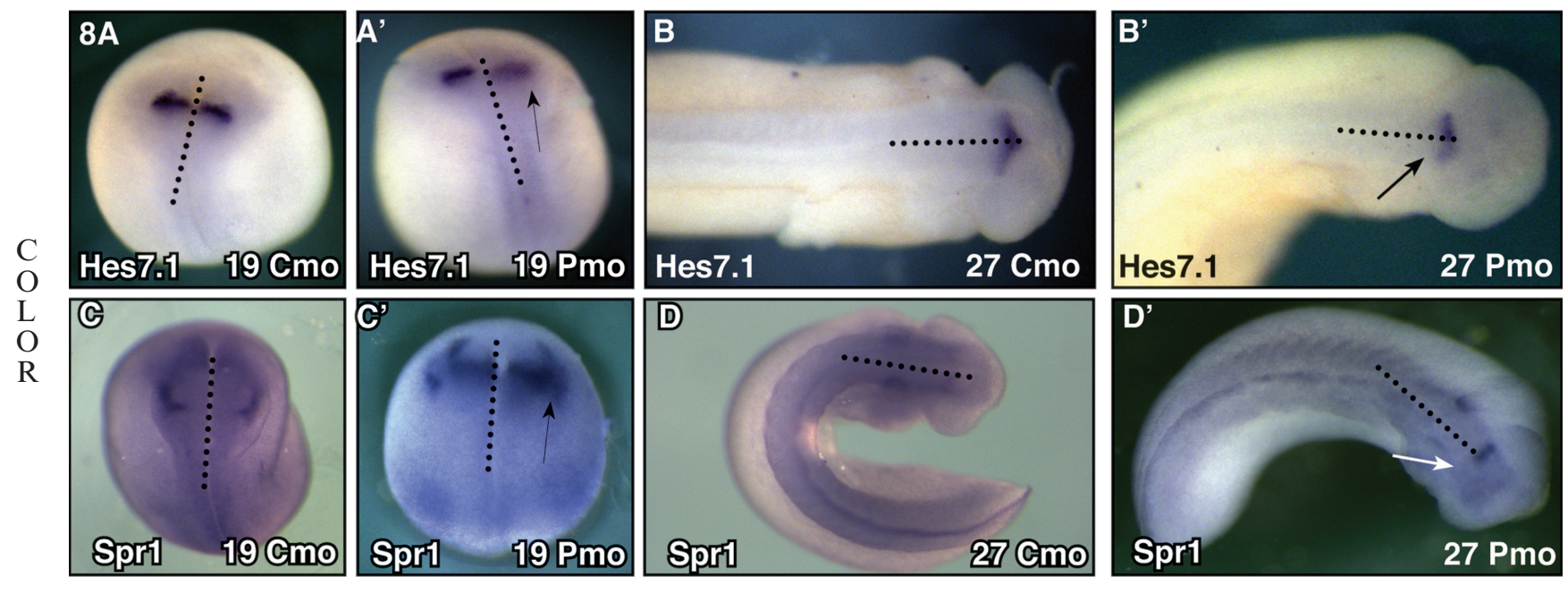

Fig. 8. 
the other RBPs, including Rbp4l's closest human homologue RBP4, are synthesized in the liver, bind to retinol in the blood (serum RBPs), and they transport retinol throughout the body to target cells (Goodman, 1981). Human PITX3 maps to $10 \mathrm{q} 25$, and this is close to human $R B P 4$ and several retinoid synthetic $C Y P$ loci at 10q24 (Gray et al., 1997). According to the Ancora resource, the region near Pitx 3 is replete with highly conserved non-coding elements, so it is tempting to speculate that the genes are embedded within a conserved genome regulatory block (Kikuta et al., 2007; Engstrom et al., 2008).

Expression of $R b p 4 l$ is first detected by RT-PCR around stage 17 and increases past stage 35 (Fig. 3B). In situ hybridization shows that expression of this transcript concentrates in the lens area and as a pronounced spot along the midline on the top of the brain. It expresses at lower levels in the craniofacial region and somites (Fig. 3C-E). These expression patterns are distinct from those reported for RBP4 and purpurin. RT-PCR analysis was performed and confirmed microarray trends: morphants demon- strated an increase in expression at stage 19 (1.84-fold) and 27 (2.88-fold; Fig. 3B). Consistent with the microarray and RT-PCR data, the gene undergoes up-regulation as a consequence of Pitx3 knockdown (Fig. 3F). Because $R b p 4 l$ expression in Pitx 3 morphants is broadly up-regulated in the craniofacial region, our supposition is that Pitx3 exerts its effects upon this gene earlier than the lens stage, and when Pitx3 expression is more expansive. The murine homolog, $R b p 4$, is also affected by Pitx3 depletion in Aphakia mutants (Münster, 2005). Taken together, the results for this novel retinol binding protein show the possibility of acting downstream of Pitx3 in lens developmental pathways, where both genes are expressed.

Galectin IX is expressed in eye field and retina. One of the EST sequences from the microarray data identified mostly with the Galectin family, and represents a new family member (Fig. 4). We identify this sequence as a Galectin IX (GenBank accession no. JN975639). It is related to the tectonin family that encode beta-propeller repeats: the microar-

Fig. 6. In situ hybridization analysis for putative Pitx3 target genes Obscnl and Baz2b. Visual comparisons of gene expression patterns between control-morpholino (Cmo) and Pitx3-morpholino (Pmo) right side-injected embryos. A: Obschl shows a loss of expression in the branchial arches (black arrow), otic vesicle, and retina when treated at stage 27 with Pmo $\left(A^{\prime}\right)$ versus Cmo (A). B: Baz2b is substantially reduced in response to Pmo $\left(\mathrm{B}^{\prime}\right)$ in the retinal layer of the optic protuberance (white arrow), as well as in the pronephros and in the anterior region of the dorsal axis, when compared with $\mathrm{Cmo}(\mathrm{B})$.

Fig. 7. Characterization of a novel transcript, Baz2b, in $X$. laevis. A: Protein alignment showing amino acid similarities between Baz2B homologs across organisms. B: Temporal expression of Baz2b throughout embryonic stages of development show expression as a maternal transcript in the egg " $E$ " and throughout development to tailbud stage, with slight reductions in transcript level at stages 10 and 19. B Confirmation of microarray predictions by means of reverse transcriptase-polymerase chain reaction (RT-PCR) show abolished expression at stage 27 in response to Pitx3-morpholino (Pmo) when compared with control-morpholino (Cmo) and wildtype (WT) embryos. C-E: Baz2b expression at stages 21 (C), 31 (D), and 35 (E) is concentrated in the developing eye, as well as the branchial arches and otic vesicle. Dark expression is seen in the pronephros, persisting in the tubules $(E)$. $\mathbf{F}$ : A schematic diagram of Baz2b protein depicting various domains characteristic of Baz2B: methyl-CpG binding domain (MBD), DNA binding domain (DDT), zinc finger domain (Z), adjacent to the bromodomain (BR). GenBank accession numbers used to generate phylogenetic tree $(\mathrm{A})$ are as follows: xBaz2b BQ400337 (X. laevis), mBaz2b BC150814 (mouse), rBaz2b NM_001108260 (rat), hBAZ2B NM_013450 (human), cBaz2b NM_204677 (chick), xtBaz2b BC166361 (X. tropicalis).

Fig. 8. In situ hybridization analysis for putative brain targets of Pitx3. Comparisons of gene expression patterns between right-side injected control-morpholino $(\mathrm{Cmo})$ or Pitx3-morpholino (Pmo) embryos and their untreated contralateral control. A-B': Hes7.1 at stage 19 shows decreased expression in the midbrain hindbrain boundary or isthmus (black arrow) in response to Pmo $\left(A^{\prime}\right)$ versus $C m o(A)$ and again at stage 27 Pmo $\left(B^{\prime}\right)$ (black arrow) versus $C m o(B)$. C-D': Spr1 stained embryos show increased expression (black arrow) at stage 19 when treated with Pmo $\left(C^{\prime}\right)$, where no change in expression is observed with $\mathrm{Cmo}(\mathrm{C})$. At stage 27, Spr1 expression in the isthmus is abolished on the Pmo side $\left(D^{\prime}\right)$ (white arrow). Dotted line represents the midline of the embryo, separating injected right-side from contralateral left-side control.

ray reports a change in transcript levels at stage 19 (diminished to a fractional level of 0.15 ) and stage 27 (diminished to 0.25 of its former level). The function of a galectin can be extremely varied: it has intracellular and extracellular functions in cell adhesion, migration, proliferation, and apoptosis and that are stage- and tissue-specific (Cooper and Barondes, 1999).

Galectin IX, a gene uncharacterized with regard to expression patterns until this study, expresses in eye field and later in both lens and retina (Fig. 4). Little is known of its promoter structure, so it is early to speculate whether or not the gene is a direct target of Pitx3. In Xenopus alone, 12 different galectin proteins have been identified, numbered in order of discovery, and can be identified by means of galactose-binding ability and protein motifs, specifically carbohydrate recognition domains (Shoji et al., 2003). Other Galectin family members are expressed throughout the embryo in specific spatiotemporal patterns, suggesting varied developmental roles for each protein (Shoji et al., 2003). Additional galectins were identified in the microarray data: Galectin IIb (St.19 2.37-Fold), Galectin I (St.19 2.26-Fold, St.27 0.44-Fold), Galectin IIIb (St.19 0.30-Fold), Galectin IIa (St.19-0.29), Galectin IIIa (St.270.41 ). As a candidate Galectin, further functional assessment for galactosebinding affinity will be necessary to firmly classify this novel protein within the galectin family (Cooper and Barondes, 1999). Using an NIBB clone (XL103j23) we performed in situ hybridization to visualize the expression pattern of this novel transcript, which appears to be concentrated in the presumptive pronephros and eye regions (Fig. 4C-E). Expression begins at gastrulation, fades and then increases gradually beginning at neurulation (Fig. 4B). Curiously, RT-PCR for microarray confirmation (Fig. 3B) shows a fractional increase in expression at stage 19 (5.28), but the expected slight decrease at stage $27(0.83)$ in morphants. This interaction is likely indirect because, even though expression patterns of Pitx 3 and Galectin IX overlap, in situ hybridizations do not demonstrate obvious changes of Galectin $I X$ expression in morphants. 


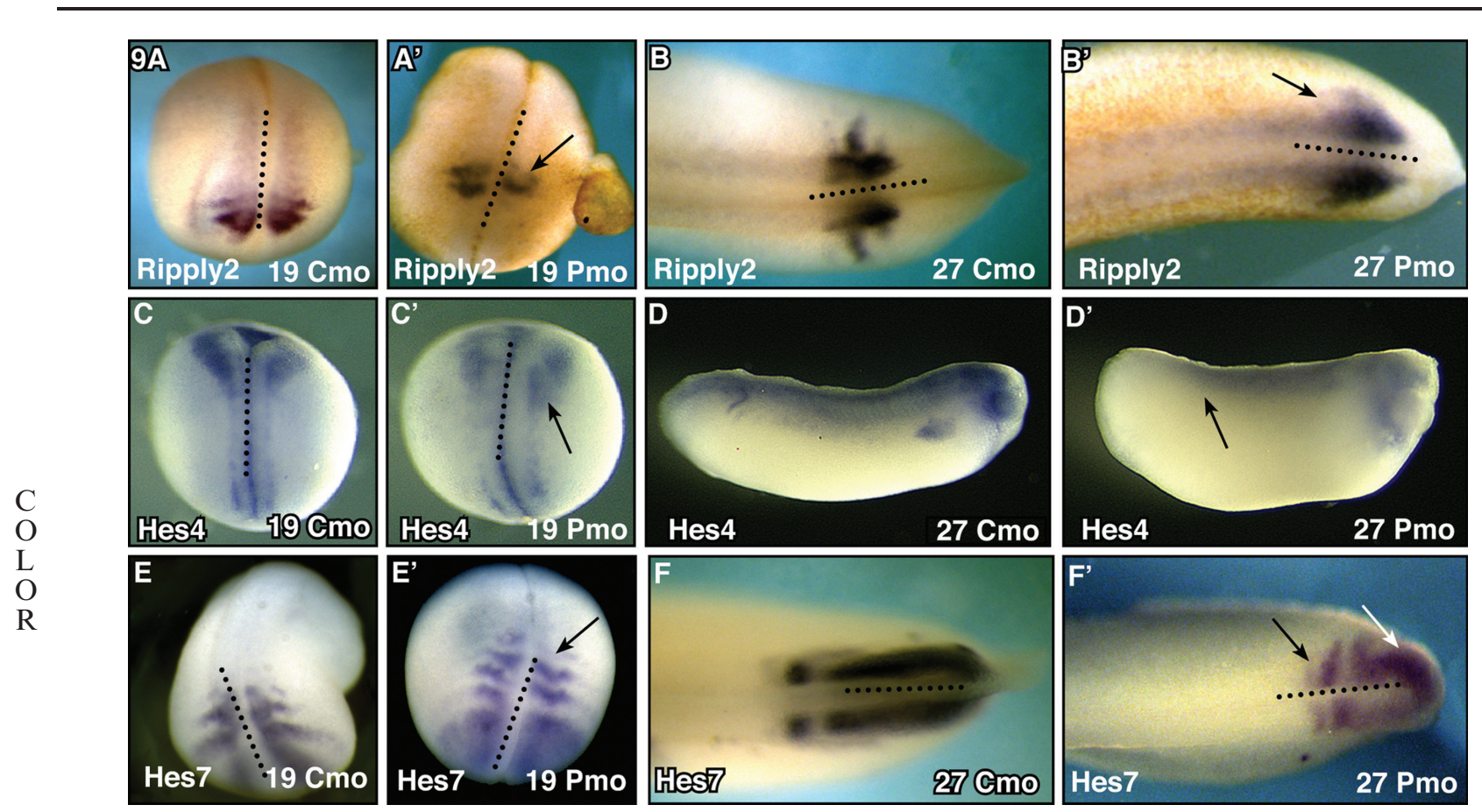

Fig. 9. In situ hybridization analysis for putative segmentation targets of Pitx3. Visual comparisons of gene expression patterns between rightside injected control-morpholino (Cmo) or Pitx3-morpholino (Pmo) embryos and contralateral control. A-B': Ripply2 expression, showing as two stripes in the presomitic mesoderm, shows an anterior shift (black arrow) in expression at stage 19 when treated with Pmo ( $\left.A^{\prime}\right)$ instead of Cmo ( $\left.A\right)$. At stage 27, Ripply2 expression pattern loses its distinct shape and becomes unrestricted in response to Pmo ( $\left.\mathrm{B}^{\prime}\right)$, whereas with $\mathrm{Cmo}$ treatment, precise patterning of this gene expression remains intact $(B)$. C-D': Hes4 expression becomes blurred in Pmo-treated embryos at stage 19 ( $\left.C^{\prime}\right)$ and at stage $27\left(\mathrm{D}^{\prime}\right)$ Hes 4 expression is absent in the presomitic mesoderm (black arrow) and pronephros areas, compared with Cmo-treated embryos (D). E-F': Hes7 no longer expresses in the most anterior stripe (black arrow), and the remaining two stripes are shifted anteriorly in comparison to the contralateral control $\left(E^{\prime}\right)$. At stage 27 , on the Pmo side of the embryo $\left(F^{\prime}\right)$, Hes7 shows increased expression in the presomitic mesoderm (white arrow) and again an anterior shift of the striped pattern (black arrow). Dotted line represents the midline of the embryo, separating injected right-side from contralateral left-side control.

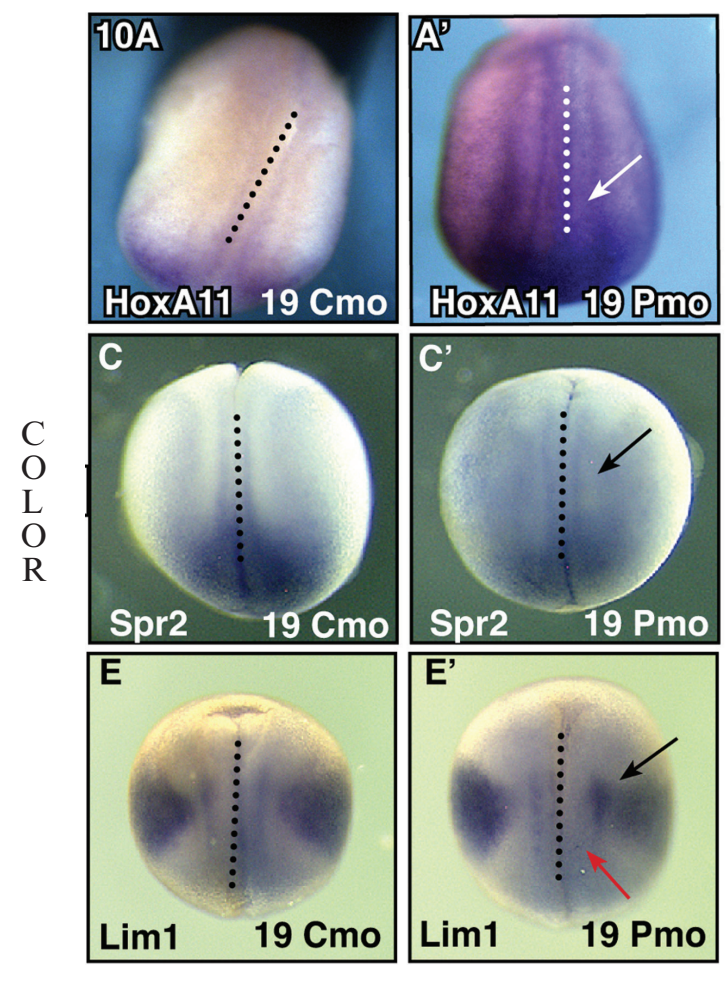

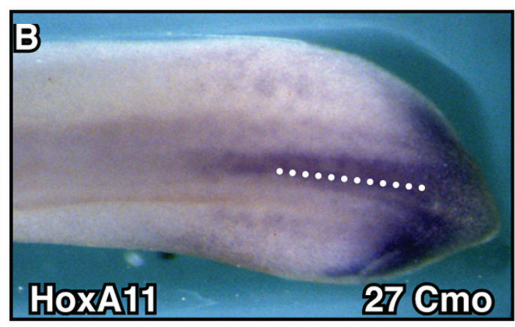
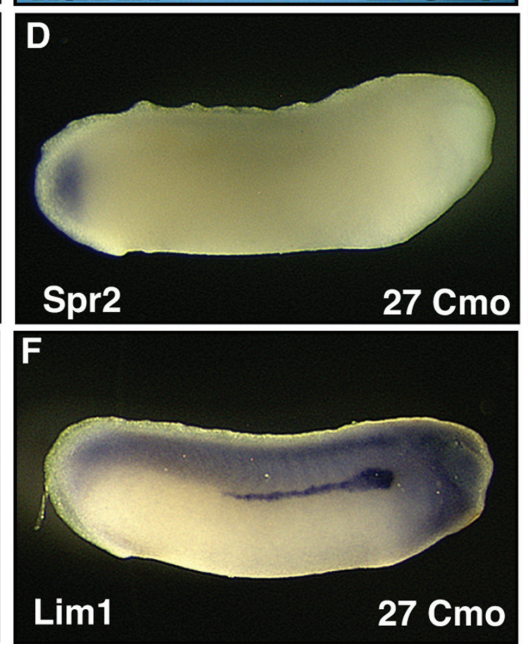
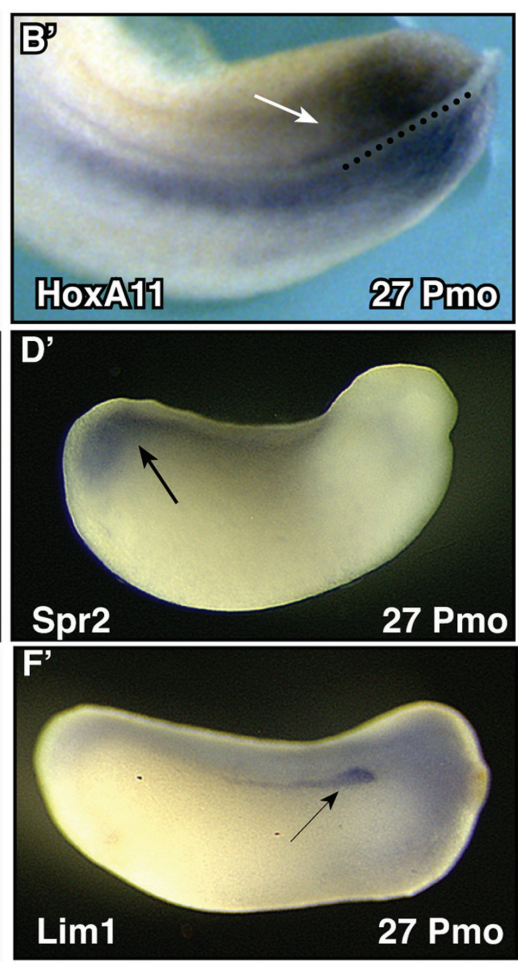

Fig. 10. 


\section{Novel Xenopus Retinol} Dehydrogenase (Rdh16). An EST sequence found in the microarray data can be identified as retinol dehydrogenase 16 (Rdh16) (Fig. 5). Because retinoic acid is pertinent to many developmental processes, and Pitx3 has already been shown to regulate an aldehyde dehydrogenase, AHD2 (Jacobs et al., 2007), this sequence is interesting as a putative downstream target of Pitx3. Retinol dehydrogenases are enzymes that catalyze the conversion of retinol (vitamin A) to retinal, an intermediate in the biosynthesis pathway of retinoic acid (Pares et al., 2008). These enzymes belong to the short-chain dehydrogenase/reductase (SDR) family. Their substrate is retinol bound to CRBP (cellular retinol binding protein) (Napoli et al., 1991) and they appear to be differentially expressed in different tissues (Chai et al., 1996). Their differential expression suggests tissue-specific roles for different family members. Xenopus Rdh16 shows $51 \%$ similarity to human 11-cis $R D H$. The 11-cis RDH is synthesized in the retinal pigmented epithelium, is necessary for the generation of 11-cis retinaldehyde from retinol, and binds visual pigments in the eye (Wald, 1968; Simon et al., 1995, 1996). Microarray predicts a fold change of 6.288 at stage 19 and 2.758 at stage 27 for this transcript. We were unable to confirm this by RT-PCR (Fig. 5B) or in situ hybridization. We rule this gene out as a Pitx3 target.

The expression of this retinol dehydrogenase appears only in tailbud stages and is concentrated in the retinal layer of the developing retina, peripheral lens, otic vesicle, branchial arches, and along the anteroposterior axis in a gradient intensified at the posterior half (Fig. 5C-E). If this gene is a homolog of human 11-cis $R D H$, the expression in the eye would support a conserved functional role.
Novel Xenopus Genes ObscurinLike and Chromatin-Remodeling Protein Baz2b. Other genes may be indirect targets of Pitx3 such as obscurin-like (Obscnl) in the eye field and branchial arches (Fig. 6A), and a chromatin remodeling gene $B a z 2 b$ (Figs. 6B, 7). Obscnl, is an EST weakly similar to obscurin, cytoskeletal calmodulin, and titin-interacting RhoGEF. Because neither gene's expression pattern is altered in all Pitx3-expressing domains, it seems likely that they are affected by the morphological changes induced by Pitx3 knockdown, and thus should be considered indirectly affected.

The EST with homology to the BAZ family of bromodomain-containing proteins (bromodomain adjacent to zinc finger) is tentatively assigned the designation Xenopus Baz2b (GenBank accession no. JN975638). The clone represents the $5^{\prime}$ half of a sequence encoding the $\mathrm{N}$-terminus (921aa). This protein family contains a conserved bromodomain at the $\mathrm{C}$ terminus, adjacent to a PHD zinc finger motif (Fig. 7F). Bromodomains, capable of binding acetyl-lysine residues, are often found in proteins with histone acetyltransferase (HAT) activity, and they are thought to play a role in chromatin-dependent gene regulation by unwinding histoneDNA complexes (Zeng and Zhou, 2002). Baz2b may have the ability to bind methylated $\mathrm{CpG}$ regions through a methyl-CpG binding domain (MBD; Fig. 4F). There is some evidence of BAZ proteins having the ability to interact with human homologs of ISWI, which in Drosophila, binds the BAZ1 protein homolog Acf1 to form the ACF chromatin remodeling complex (Ito et al., 1999; Jones et al., 2000a,b).

The microarray predicts that at stage 19 this transcript decreases in morphants to a fraction of 0.4 and at stage 27 to a fraction of 0.27 . Unfortu-

Fig. 10. In situ hybridization analysis for putative tailbud targets of Pitx3. A-B': HoxA11 shows decreased posterior expression in the tailbud region (white arrows) of Pmo embryos at stages $19\left(\mathrm{~A}^{\prime}\right)$ and $27\left(\mathrm{~B}^{\prime}\right)$; $\mathbf{C}-\mathbf{D}^{\prime}$ : Spr2 displays a broader and larger domain of expression (black arrows) when treated with Pmo, both at stage $19\left(\mathrm{C}^{\prime}\right)$ and $27\left(\mathrm{D}^{\prime}\right)$, compared with Cmo-treated embryos (C, D). E-F': Lim1 expression disappears from paraxial mesoderm (red arrow) and is up-regulated in lateral mesoderm (black arrow) at stage 19 when treated with Pmo ( $\left.E^{\prime}\right)$. At stage $27\left(\mathrm{~F}^{\prime}\right)$, Pmo reduces Lim1 expression in the developing pronephros (black arrow) and in the head mesenchyme and along the dorsal axis.

nately, by RT-PCR stage 19 transcript is just at the limit of detectability. RTPCR shows expression throughout embryogenesis, beginning as a maternal transcript in the oocyte and persisting through tailbud stages, and confirms the microarray data by showing a drastic decrease in expression at stage 27 (to a fraction of 0.086 ), with undetected expression at stage 19 (Fig. 7B). Its spatial expression pattern, initially quite diffuse (not shown), condenses around the developing eye and pronephric structures during tailbud stages (Fig. 7C-E).

Since Pitx 3 has been shown to play major roles in both the lens and retina development, these genes correlate with a role for this transcription factor in specifying lens placode, initiating lens differentiation, and in inducing retina (Khosrowshahian et al., 2005).

\section{Brain expression.}

One candidate sequence was highly similar to Hes-related 1, and is tentatively re-assigned the name Hes7.1 based upon homology to the X. tropicalis and human genes. This gene likely specifies the frog midbrain/hindbrain boundary, or isthmus (Shinga et al., 2001; Takada et al., 2005). The isthmus is an important organizer of brain regionalization and consequent patterning (Nakamura and Watanabe, 2005). When murine Hes 1 is disrupted, brain patterning mediated through the isthmus is damaged, and the mesencephalic dopaminergic (mDA) neurons fail to thrive. The same authors report that expression of both Pitx3 and tyrosine hydroxylase is abnormal (Kameda et al., 2011). Because the related Xenopus homolog possesses 11 putative Pitx binding motifs, future studies should be sensitive to the possibility that Hes1/Hes7.1 and Pitx3 are engaged in a reciprocally regulatory relationship. Spr1, a Xenopus laevis transcription factor that is related to the human $S p 1$ and mouse Sp5 zinc finger genes, is expressed in the forebrain as well as the isthmus, where $e F G F$ also plays a role (Isaacs et al., 1992; Ossipova et al., 2002). Both Spr1 and Hes7.1 show decreased expression in the isthmus in response to Pitx3-morpholino as assessed by in situ hybridization (Fig. 8). 
Unfortunately, tyrosine hydroxylase, a gene critical to differentiation of dopaminergic neurons (mDA) of the substantia nigra, is not represented on the microarray. However, Wnt1, an early stage marker for murine isthmus (Würst et al., 1994), is both represented on the microarray and down-regulated (Table 2). Only an unworkably small fragment of the gene has been cloned in frog (Wolda and Moon, 1992). Because Pitx3 is especially pertinent for the differentiation and maintenance of mDA neurons and because the isthmus is critical to development of the substantia nigra (Marchand and Poirier, 1983), it is tempting to speculate that this Pitx3 effect is mediated through control of isthmus patterning at early developmental stages.

The expression patterns of Lim1 will be discussed a greater length later, however, it is worth noting in the context of isthmus and substantia nigra (structures that are induced and patterned early by Lim 1 [Shawlot and Behringer, 1995]), that although the RT-PCR assays did not confirm the microarray data, nevertheless, in situ hybridization did. Moreover, Lim1 possesses 5 evolutionarily conserved Pitx3 binding motifs. Based upon our preliminary slate of putative signaling partners, our suspicion is that Pitx 3 plays a heretofore uncharacterized role during gastrulation to pattern anterior-most structuresprevious work has indicated that it expresses in fish hypoblast (Dutta et al., 2005), and somewhere in Xenopus pregastrula (RT-PCR, uncharacterized and low-expression location; Khosrowshahian et al., 2005).

\section{Segmentation and tailbud signaling.}

The Ripply family, Ripply1 (bowline), Ripply2 (ledgerline, stripy) and Ripply3 serve as transcriptional repressors that are necessary for proper boundary formation during somitogenesis. The Ripply genes appear to act by balancing the FGF/RA signaling wave front and thereby regulate the emergence of new somites: this regulation is likely mediated by interaction with T-box genes (Chan et al., 2006; Kawamura et al., 2008; Hitachi et al., 2009). It is interesting that both $T b x 4$ and $T b x 5$ go down in our data set $(0.237$ and 0.436 for each of the two Tbx4 probands, and 0.432 for Tbx5). Ripply2, Hes4, and Hes7 are perturbed in Pitx3 morphants (Fig. 9), and Ripply 2 possesses 20 Pitx 3 binding sites in its 5'-UTR. Hes 7 expression patterns confirmed the microarray data, however, triplicate RT-PCR reactions did not substantiate this statistically. We note that RT-PCR consistency has historically been a problem in microarray studies (Altmann et al., 2001; Buchtova et al., 2010), and given the presence of 10 Pitx3 binding motifs within the $5^{\prime}$ UTR of Hes7, we are inclined to pursue this gene's candidacy further. Perturbation of Hes4 is complex: it appears to up-regulate at early stages, to remain unchanged through neurulation, but to be inhibited at tailbud stages (Smoczer et al., In Press). Hes 4 and Hes 7 are factors that function downstream of the Notch pathway during somitogenesis and that mediate segmental patterning of the presomitic mesoderm where they serve as components of the segmentation clock (Jen et al., 1999; Tsuji et al., 2003; Murato et al., 2007). Recently, presomitic expression has been reported for Pitx 3 and its perturbation results in anomalous segmentation presenting as a bent dorsal axis and aberrant somite morphogenesis (Smoczer et al., In Press). Ripply2 morphants also produce bent dorsal axes and shift Hes4 and Hes 7 expression patterns anteriorly (Chan et al., 2006). Further research is necessary to deduce which of these are direct downstream targets of Pitx3, but a good starting point would be to test if Pitx3 modulates Ripply2 and thereby indirectly alters expression of the Hes genes.

Both $e F G F$ and $R X R \alpha$ are transcribed in the tailbud and thus may be factors that are affected by Ripply 2 (Chan et al., 2006). eFGF extends to the posterior of the body axis and into the proliferating tailbud where notochord and somites continue to emerge. $e F G F$ is also expressed later in the myotome of the trunk (Isaacs et al., 1992). Both $e F G F$ and $R X R \alpha$ appear regulated by Pitx3 in the microarray dataset, but neither confirm by RT-PCR. The expression levels are too low to be reliably detected by in situ hybridization at stage 19 and 27; however, both possess consensus Pitx3 binding motifs in their respective $5^{\prime}$-UTR. Given the effects of Pitx3 perturbation upon the somitogenesis- and tailbud-expressing genes HoxA11, Spr2, and Lim1 (Fig. 10), it might be worth re-examining their failed candidacy as targets.

Spr2 and HoxA11 are affected by Pitx3 mis-regulation (Fig. 10). HoxA11 specifies positional identity along the anteroposterior axis and is largely expressed in the posterior notochord and tailbud mesoderm (Lombardo and Slack, 2001). Other Hox genes are affected to a lesser, though still significant fractional degree: HoxA13 (2.4), and HoxA10 (0.37). The differential effect upon these genes renders an indirect mediation by retinoid metabolism unlikely. Lim 1 expression undergoes a complex modulation of expression: lateral mesoderm expression increases, while in paraxial mesoderm, expression is abolished. Spr2 and Vent2 are expressed in the developing tailbud (Ladher et al., 1996; Ossipova et al., 2002), so effects in this domain would also be reflected in the microarray.

\section{Indirectly characterized early perturbation effects.}

Although the microarray data was analyzed for embryos at stages 19 and 27 , a significant number of candidates are pertinent for early patterning of the embryo, and moreover, are known to interact with each other in a manner consistent with Pitx3 impinging upon their respective regulatory networks. Pitx3 has been detected at early stages in the embryo (stage 8; Khosrowshahian et al., 2005) suggesting an unknown function for this transcription factor at earlier stages. One of our candidate targets, Vent2, provides ventralizing information and perhaps signals for the differentiation of the epidermis (Ladher et al., 1996). This factor directly down-regulates the homeobox gene Goosecoid (Gsc), which is expressed in Spemann's organizer and then becomes undetectable as the embryo undergoes neurulation (Cho et al., 1991; Trindade et al., 1999). Gsc is responsible for the development of dorsal structures (Cho et al., 1991). These two genes, Vent-2 
TABLE 3. Parameters and Primer Sequences Used in RT-PCR Experiments

\begin{tabular}{|c|c|c|c|c|c|}
\hline Gene & Primers & Size & $\begin{array}{l}\text { Anneal } \\
\text { temp }\end{array}$ & GenBank no. & Reference \\
\hline ODC & $\begin{array}{l}\text { Sense: } 5^{\prime} \text { - GTC AAT GAT GGA GTG TAT G - } 3^{\prime} \\
\text { Antisense: } 5^{\prime} \text { - TCC ATT CCG CTC TCC TGA - } 3^{\prime}\end{array}$ & $385 \mathrm{bp}$ & $57^{\circ} \mathrm{C}$ & & XenBase \\
\hline $\operatorname{Lim} 1$ & $\begin{array}{l}\text { Sense: } 5^{\prime} \text { - CCG ACA CAT AAG GGA GCA GC - } 3^{\prime} \\
\text { Antisense: } 5^{\prime} \text { - CTG GTG GGT GTG ACA AAT GG }-3^{\prime}\end{array}$ & $573 \mathrm{bp}$ & $60^{\circ} \mathrm{C}$ & X63889 & Homemade \\
\hline Spr1 & $\begin{array}{l}\text { Sense: } 5^{\prime} \text { - CCA GGT ACA AGT CCT ACT GA - } 3^{\prime} \\
\text { Antisense: } 5^{\prime} \text { - GAG TGC CAC CTC AAA TGA GC - } 3^{\prime}\end{array}$ & $752 \mathrm{bp}$ & $54^{\circ} \mathrm{C}$ & AY062264 & $\begin{array}{l}\text { Ossipova } \\
\text { et al., } 2002\end{array}$ \\
\hline Spr2 & $\begin{array}{l}\text { Sense: } 5^{\prime} \text { - CAA ACT GTT GCC TCT CAT GAG - } 3^{\prime} \\
\text { Antisense: } 5^{\prime} \text { - CAC TTA CAC CTC CGG CAG CGC - } 3^{\prime}\end{array}$ & $380 \mathrm{bp}$ & $54^{\circ} \mathrm{C}$ & AY062263 & $\begin{array}{l}\text { Ossipova } \\
\text { et al., } 2002\end{array}$ \\
\hline Vent2 & $\begin{array}{l}\text { Sense: } 5^{\prime} \text { - GCT TTC TCC TCG GTT GAA TG - } 3^{\prime} \\
\text { Antisense: } 5^{\prime} \text { - TCT CCT TCA GGG GCT GTA GA - } 3^{\prime}\end{array}$ & $461 \mathrm{bp}$ & $57^{\circ} \mathrm{C}$ & X98454 & Homemade \\
\hline Hes4 & $\begin{array}{l}\text { Sense: } 5^{\prime} \text { - GCA CGA ACG AAG TCA CAC GA - } 3^{\prime} \\
\text { Antisense: } 5^{\prime} \text { - GCT GGG TTG GGA ATG AGG AAA G - } 3^{\prime}\end{array}$ & $297 \mathrm{bp}$ & $65^{\circ} \mathrm{C}$ & AF139914 & Homemade \\
\hline Hes7.1 & $\begin{array}{l}\text { Sense: } 5^{\prime} \text { - TGT AAT GTG CTC AAA TGG CG - } 3^{\prime} \\
\text { Antisense: } 5^{\prime} \text { - TCC GTC AGC CCT ACA AAG AC - } 3\end{array}$ & $336 \mathrm{bp}$ & $54^{\circ} \mathrm{C}$ & BJ088128 & Homemade \\
\hline Obscnl & $\begin{array}{l}\text { Sense: 5' - ACA GTA TGG TTC ACA GCC - 3' } \\
\text { Antisense: 5' - CAG TTG GCA CAT CAA TCC AG - 3' }\end{array}$ & $283 \mathrm{bp}$ & $57^{\circ} \mathrm{C}$ & BJ085487 & Homemade \\
\hline Gsc & $\begin{array}{l}\text { Sense: } 5^{\prime} \text { - ACA ACT GGA AGC ACT GGA - } 3^{\prime} \\
\text { Antisense: } 5^{\prime} \text { - TCT TAT TCC AGA GGA ACC - } 3^{\prime}\end{array}$ & $279 \mathrm{bp}$ & $52^{\circ} \mathrm{C}$ & M81481 & XenBase \\
\hline $\mathrm{RXR} \alpha$ & $\begin{array}{l}\text { Sense: } 5^{\prime} \text { - AAG ATA CTT GAG GCG GAG CA - } 3^{\prime} \\
\text { Antisense: } 5^{\prime} \text { - TTC GGG GTA TTT CTG TTT GC - } 3^{\prime}\end{array}$ & $531 \mathrm{bp}$ & $54^{\circ} \mathrm{C}$ & L11446 & Homemade \\
\hline L-Maf & $\begin{array}{l}\text { Sense: } 5^{\prime} \text { - CTT GCT CCT CCT CAA TCT CTG G - } 3^{\prime} \\
\text { Antisense: } 5^{\prime} \text {-CCG ACA AAG GCG AAA GCT GGT G - } 3^{\prime}\end{array}$ & $331 \mathrm{bp}$ & $54^{\circ} \mathrm{C}$ & AF202059 & $\begin{array}{l}\text { Ishibashi and } \\
\quad \text { Yasuda, } 2001\end{array}$ \\
\hline eFGF & $\begin{array}{l}\text { Sense: } 5^{\prime} \text { - TTA CCG GAC GGA AGG ATA - } 3^{\prime} \\
\text { Antisense: } 5^{\prime} \text { - CCT CGA TTC GTA AGC GTT - } 3^{\prime}\end{array}$ & $222 \mathrm{bp}$ & $56^{\circ} \mathrm{C}$ & X62594 & Kroll Lab \\
\hline Bix 4 & $\begin{array}{l}\text { Sense: } 5^{\prime} \text { - CAG AAC AGG AGA TCA AAA GC }-3^{\prime} \\
\text { Antisense: } 5^{\prime} \text { - CGG GTA GGT ACT AGA TGC TG }-3 \text { ' }\end{array}$ & $414 \mathrm{bp}$ & $54^{\circ} \mathrm{C}$ & AF079562 & Homemade \\
\hline Hes7 & $\begin{array}{l}\text { Sense: 5' - TGT TGG CTT GAA AGG TTT GT - } 3^{\prime} \\
\text { Antisense: 5' - CTC AAA ATG TGT CAT AAT CCA - } 3^{\prime}\end{array}$ & $394 \mathrm{bp}$ & $60^{\circ} \mathrm{C}$ & BJ058661 & Homemade \\
\hline Ripply2 & $\begin{array}{l}\text { Sense: 5' - ATG GAG CCG AAT CAA CAG C - } 3^{\prime} \\
\text { Antisense: 5' - TGT CTT CCT CTT CAG AGT CA - } 3^{\prime}\end{array}$ & $352 \mathrm{bp}$ & $57^{\circ} \mathrm{C}$ & $\mathrm{AB} 073615$ & Homemade \\
\hline Crybb1 & $\begin{array}{l}\text { Sense: 5' - CGT GGT GAG ATG TTT ATC CTG GAG - } 3^{\prime} \\
\text { Antisense: 5' - CCT TCT GGT GCC ATT GAT TGT CTC - } 3^{\prime}\end{array}$ & $394 \mathrm{bp}$ & $60^{\circ} \mathrm{C}$ & CD303346 & Homemade \\
\hline Pax6 & $\begin{array}{l}\text { Sense: 5' - GCA ACC TGG CGA GCG ATA AGC - } 3^{\prime} \\
\text { Antisense: 5' -CCT GCC GTC TCT GGT TCC GTA GTT - } 3^{\prime}\end{array}$ & $448 \mathrm{bp}$ & $56^{\circ} \mathrm{C}$ & U77532 & $\begin{array}{l}\text { Zuber } \\
\quad \text { et al., } 2003\end{array}$ \\
\hline HoxA11 & $\begin{array}{l}\text { Sense: 5' - AAT CCC TCC AAT GTC TAC CAC C - } 3^{\prime} \\
\text { Antisense: 5' - CTG GTA TTT GGT ATA CGG GCA C - }\end{array}$ & $363 \mathrm{bp}$ & $56^{\circ} \mathrm{C}$ & AJ319668 & $\begin{array}{l}\text { Slack } \\
\quad \text { et al., } 2001\end{array}$ \\
\hline Rbp4l & $\begin{array}{l}\text { Sense: 5' - AGA TGC AAT GCT CAG TCC T - 3' } \\
\text { Antisense: 5' - GCG GGA GAA TAT AAT AGA ATA - 3' }\end{array}$ & $432 \mathrm{bp}$ & $54^{\circ} \mathrm{C}$ & CD362061 & Homemade \\
\hline GalectinIX & $\begin{array}{l}\text { Sense: 5' - CCC GTG CCT GGT ATT TCA - 3' } \\
\text { Antisense: 5' - ACC TGG CTG GAG TGA ACA - 3' }\end{array}$ & $448 \mathrm{bp}$ & $55^{\circ} \mathrm{C}$ & BJ056659 & Homemade \\
\hline Baz2b & $\begin{array}{l}\text { Sense: } 5 \text { - AAG ATG ATG ATG AGG ACG A - 3' } \\
\text { Antisense: } 5 \text { ' - CCA TTT TAG CCT GCT GTT TC - } 3\end{array}$ & $837 \mathrm{bp}$ & $55^{\circ} \mathrm{C}$ & BQ400337 & Homemade \\
\hline Rdh16 & $\begin{array}{l}\text { Sense: 5' - CTG CGA CTC TGG GTT TGG A - 3' } \\
\text { Antisense: 5' - TCA TAG CCG GCA GAG TAG - 3' }\end{array}$ & $750 \mathrm{bp}$ & $57^{\circ} \mathrm{C}$ & BG514525 & Homemade \\
\hline
\end{tabular}

and Gsc, play antagonistic roles in the establishment of the dorsoventral axis. Lim 1 expression peaks at gastrulation in Spemann's organizer, and has the ability to directly activate Gsc and maintain its expression in the prechordal plate (Mochizuki et al., 2000). All three are represented as Pitx3-sensitive in the microarray; however, Gsc expresses too early to have been monitored in our riboprobe in situ hybridization although it should be noted that Gsc possesses 14 Pitx3 motifs in its $5^{\prime}$-UTR.
Bix4 is a Brachyury-inducible homeobox-containing gene and is thought to induce both mesoderm and endoderm formation depending on the concentration of its encoded protein (Tada et al., 1998). It expresses earlier than we monitored by in situ hybridization at stages 19 or 27. Similarly, $e F G F$ and $R X R \alpha$ are also expressed early in development, well before the stages that we assessed. $e F G F$ is most similar to $F G F-6$ and $F G F-4$ in mammals, yet may represent a novel FGF secreted factor that has both mesoderm-inducing properties and roles in anteroposterior patterning (Isaacs et al., 1994). $R X R \alpha$ encodes a retinoid $\mathrm{X}$ receptor that is part of the nuclear receptor family that mediates the effects of retinoic acid upon embryos. Expression of $R X R \alpha$ begins as a maternal transcript in the oocyte, and then is temporarily abolished before gastrulation, leading to a role for this receptor in early patterning of the embryo (Blumberg et al., 1992). RA provides positional information and helps to pattern the 
TABLE 4. Gene-Specific Information Regarding Restriction Enzymes and RNA Polymerases Used to Generate Riboprobes for In Situ Hybridization Experiments

\begin{tabular}{|c|c|c|c|c|}
\hline Gene & Plasmid & Restriction enzyme & RNA Polymerase & Reference/source \\
\hline $\operatorname{Lim} 1$ & pBSKS+/Xlim-1 (pXH32) & XhoI & $\mathrm{T} 7$ & Dawid, I. (NICHD) \\
\hline Vent2 & pBS-XOM & EcoRI & $\mathrm{T} 7$ & Ladher et al., 1996 \\
\hline Spr1 & pBSTSp1 T3/597(2-3)-2/XSPR-1 & NotI & $\mathrm{T} 3$ & Ossipova et al., 2002 \\
\hline Spr2 & pCS2+NLSmyc/XSPR-2 & XhoI & $\mathrm{T} 7$ & Ossipova, O. (unpublished) \\
\hline Hes4 & XL409i23ex & EcoRI & $\mathrm{T} 7$ & NIBB \\
\hline Rbp4l & XL060f11 & BamHI & $\mathrm{T} 7$ & NIBB \\
\hline GalectinIX & XL103j23 & EcoRI & $\mathrm{T} 7$ & NIBB \\
\hline Baz2b & 6989392 & SalI & $\mathrm{T} 7$ & I.M.A.G.E. \\
\hline Rdh16 & 9897030 & SalI & $\mathrm{T} 7$ & I.M.A.G.E \\
\hline Hes7.1 & XL091p04 & EcoRI & $\mathrm{T} 7$ & NIBB \\
\hline Obscnl & XL106a24 & EcoRI & $\mathrm{T} 7$ & NIBB \\
\hline Hes7 & XL060b05 & EcoRI & $\mathrm{T} 7$ & NIBB \\
\hline Ripply2 & pCS/ledgerline & ClaI & $\mathrm{T} 7$ & Asashima M. lab \\
\hline Crybb1 & & HindIII & $\mathrm{T} 7$ & Henry J. lab \\
\hline Pax6 & & EcoRI & SP6 & Lupo G. lab \\
\hline HoxA11 & pGMT/HoxA11 & NotI & $\mathrm{T} 7$ & Slack et al., 2001 \\
\hline
\end{tabular}

anteroposterior body axis, mostly by mediating posterior transformation of the embryo (Durston et al., 1989).

\section{Conclusion}

Microarray analysis is a useful tool to monitor the influence of a gene upon the entire transcriptome of an organism. However, the generated data set is quite elaborate and deducing pertinent trends can be a challenging process. The information represented in this study provides a global view of general developmental processes in which Pitx3 may be involved. New genetic players have been identified as putative Pitx3 targets in the already established eye and brain developmental processes. In addition, based on genes identified by the microarray, novel roles for Pitx3 can be inferred for regulation of early patterning events and the development of the anterior-posterior body axis.

\section{EXPERIMENTAL PROCEDURES}

\section{Embryo Collection and Manipulation}

Staging, de-jellying, and culturing of Xenopus laevis embryos were conducted as previously described (Nieuwkoop and Faber, 1967; Drysdale and Elinson, 1991). Animals were reared and used in accordance with University, Provincial, and Fed- eral regulations. Fluorescently labeled morpholinos for either control or experimental Pitx3 treatments were injected as previously described (Khosrowshahian et al., 2005; Smoczer et al., In Press). Essentially, 4.6-nl injections were made into the animal pole of embryos at the 1-cell stages for RNA collection and one- or two-cell stages for in situ hybridization. Injected embryos were cultured in 0.3 $\times$ MBS and 2\% Ficoll-400 (Sigma) at $17^{\circ} \mathrm{C}$ for at least $1 \mathrm{hr}$ to allow healing before being removed and allowed to develop at $12^{\circ} \mathrm{C}$ in $0.1 \times \mathrm{MBS}$.

\section{RNA Preparation and Microarray Analysis}

At staged intervals, embryos were removed for RNA isolation, lysed, and processed in Trizol as per manufacturer's instructions (Invitrogen). We then used DNAseI to remove genomic DNA, and ran the product over Qiagen RNeasy columns for purification. RNA quality was assessed using the Agilent 2100 Bioanalyzer (Agilent Technologies Inc., Palo Alto, CA) and the RNA 6000 Nano kit (Caliper Life Sciences, Mountain View, CA).

All GeneChips were processed from two biological replicates at the London Regional Genomics Centre (Robarts Research Institute, London, Ontario, Canada; http://www.lrgc.ca). Biotinylated complimentary RNA (cRNA) was prepared from $10 \mu \mathrm{g}$ of total RNA as per the Affymetrix GeneChip Technical Analysis Manual
(Affymetrix, Santa Clara, CA). Double-stranded cDNA was synthesized using SuperScriptII (Invitrogen, Carlsbad, CA) and oligo $(\mathrm{dT})_{24}$ primers. Biotin-labeled cRNA was prepared by cDNA in vitro transcription using the BioArray High-Yield RNA Transcript Labeling kit (Enzo Biochem, New York) incorporating biotinylated UTP and CTP. A total of $15 \mu \mathrm{g}$ of labeled cRNA was hybridized to Xenopus laevis GeneChips for $16 \mathrm{hr}$ at $45^{\circ} \mathrm{C}$ as described in the Affymetrix Technical Analysis Manual (Affymetrix). GeneChips were stained with Streptavidin-Phycoerythrin, followed by an antibody solution and a second Streptavidin-Phycoerythrin solution, with all liquid handling performed by a GeneChip Fluidics Station 400. GeneChips were scanned with the Affymetrix GeneChip Scanner 3000 (Affymetrix).

Signal intensities for genes were generated using GCOS1.2 (Affymetrix) using default values for the Statistical Expression algorithm parameters and a Target Signal of 150 for all probe sets and a Normalization Value of 1 . Normalization was performed in GeneSpring 7.2 (Agilent Technologies Inc., Palo Alto, CA). Data were first transformed (measurements less than 0.01 set to 0.01 ) and then normalized per chip to the 50th percentile, and per gene to control samples for each stage. We performed two biological replicates and filtered the data based upon fold change with a cut off $P$ value set at 0.05 . 


\section{RT-PCR}

cDNA was made using Omniscript reverse transcriptase (Qiagen) and Oligo $(\mathrm{dT})_{18}$ primers (Sigma) from $1 \mathrm{ug}$ total RNA for microarray confirmation and from 10uL mRNA further isolated (GenElute Direct mRNA Miniprep Kit; Sigma) for stage analysis of novel EST sequences. RT-PCR was performed at various annealing temperatures and cycle numbers, resulting in five time-points that were ultimately graphed. A cycle at the linear phase of amplification was selected for each gene and standardized against ODC. Fold change for microarray confirmation was determined by comparing gene amplification of control-morpholino-treated samples with Pitx3-morpholinotreated samples. Primers and param-

T3 eters are outline in Table 3.

\section{Whole-Mount In Situ Hybridization}

In situ hybridizations were performed according to established protocols (Harland, 1991) using digoxygenin-labeled riboprobes. We probed genes that were either two times up- or down-regulated as a consequence of Pitx3-morpholino perturbation, deemed by the microarray analysis. The probes used were generated from plasmids that were either the generous gifts of colleagues, the NIBB/NIG/ NBRP Xenopus laevis EST project, or were purchased from ATCC (see Tables). When a probe revealed a temporal and spatial expression pattern that overlapped with the known activity of Pitx3, further in situ hybridizations were conducted on specimens that had been unilaterally injected with morpholino (control- or Pitx3morpholino) at the two-cell stage: expression on the perturbed side could be compared with the contralateral control, and the trend predicted by the microarray thereby confirmed. Probes were prepared from vectors as T4 outlined in Table 4.

\section{Identification of Novel Genes}

Some of the most differentially expressed but previously uncharacterized EST sequences were explored. Their spatial expression pattern was visualized by means of in situ hybridization and the temporal expression pattern was then investigated using RT-PCR throughout embryonic stages of development. Varied stages were used to determine specific developmental events: unfertilized egg (E) and stage 5 for maternal transcripts, stage 10 (early gastrula), stage 12 (neural anlage), stage 17 (onset of somitogenesis), stage 19 (neural tube), stage 24 (tailbud), stage 27 (lens differentiation), stage 31 (cardiac looping), stage 35 (blood supply; Nieuwkoop and Faber, 1967). Phylogenic profiles and functional attributes were deduced using Blastp searches within GenBank and homolog alignments using the Megalign program of DNASTAR Lasergene 7.2.

\section{ACKNOWLEDGMENTS}

The authors thank the numerous colleagues who provided us with probes, and particularly to Dr. Kitayama and Dr. Ueno, at the NIBB, without whose patient, generous, and numerous gifts this work could not have proceeded. Thanks also to David Carter of the London Regional Genomics Center, Robarts Research Institute, London, Ontario. M.J.C. was funded by the Natural Sciences and Engineering Research Council (NSERC) of Canada. F.K.S. was supported by an NSERC PGS, and M.W. was partially supported by an Ontario Graduate Scholarship.

\section{REFERENCES}

Altmann CR, Bell E, Sczyrba A, Pun J, Bekiranov S, Gaasterland T, Brivanlou AH. 2001. Microarray-based analysis of early development in Xenopus laevis. Dev Biol 236:64-75.

Amendt BA, Sutherland LB, Semina EV, Russo AF. 1998. The molecular basis of Rieger syndrome. Analysis of Pitx2 homeodomain protein activities. J Biol Chem 273:20066-20072.

Berman P, Gray P, Chen E, Keyser K, Ehrlich D, Karten H, LaCorbiere M, Esch F, Schubert D. 1987. Sequence analysis, cellular localization, and expression of a neuroretina adhesion and cell survival molecule. Cell 51:135-142.

Blumberg B, Mangelsdorf DJ, Dyck JA, Bittner DA, Evans RM, De Robertis EM. 1992. Multiple retinoid-responsive receptors in a single cell: families of retinoid "X" receptors in the Xenopus egg. Proc Natl Acad Sci U S A 89: 2321-2325.
Buchtova M, Kuo WP, Nimmagadda S, Benson SL, Geetha-Loganathan P, Logan C, Au-Yeung T, Chiang E, Fu K, Richman JM. 2010. Whole genome microarray analysis of chicken embryo facial prominences. Dev Dyn 239: 574-591.

Cazorla P, Smidt MP, O’Malley KL, Burbach JP. 2000. A response element for the homeodomain transcription factor Ptx3 in the tyrosine hydroxylase gene promoter. J Neurochem 74:1829-1837.

Chai X, Zhai Y, Napoli JL. 1996. Cloning of a rat cDNA encoding retinol dehydrogenase isozyme type III. Gene 169: 219-222.

Chan T, Satow R, Kitagawa H, Kato S, Asashima M. 2006. Ledgerline, a novel xenopus laevis gene, regulates differentiation of presomitic mesoderm during somitogenesis. Zoolog Sci 23:689-697.

Chepelinsky AB. 2009. Structural function of MIP/aquaporin 0 in the eye lens; genetic defects lead to congenital inherited cataracts. Handb Exp Pharmacol: 265-297.

Cho KW, Blumberg B, Steinbeisser H, De Robertis EM. 1991. Molecular nature of Spemann's organizer: the role of the Xenopus homeobox gene goosecoid. Cell 67:1111-1120.

Cooper DN, Barondes SH. 1999. God must love galectins; he made so many of them. Glycobiology 9:979-984.

Coulon V, L'Honore A, Ouimette JF, Dumontier E, van den Munckhof P, Drouin J. 2007. A muscle-specific promoter directs Pitx3 gene expression in skeletal muscle cells. J Biol Chem 282: 33192-33200.

Cui W, Tomarev SI, Piatigorsky J, Chepelinsky AB, Duncan MK. 2004. Mafs, Prox1, and Pax6 can regulate chicken betaB1-crystallin gene expression. J Biol Chem 279:11088-11095.

Drysdale TA, Elinson RP. 1991. Development of the Xenopus laevis hatching gland and its relationship to surface ectoderm patterning. Development 111: 469-478.

Durston AJ, Timmermans JP, Hage WJ, Hendriks HF, de Vries NJ, Heideveld M, Nieuwkoop PD. 1989. Retinoic acid causes an anteroposterior transformation in the developing central nervous system. Nature 340:140-144.

Dutta S, Dietrich JE, Aspock G, Burdine RD, Schier A, Westerfield M, Varga ZM. 2005. pitx3 defines an equivalence domain for lens and anterior pituitary placode. Development 132:1579-1590.

Eisen JS, Smith JC. 2008. Controlling morpholino experiments: don't stop making antisense. Development 135: 1735-1743.

Engstrom PG, Fredman D, Lenhard B. 2008. Ancora: a web resource for exploring highly conserved noncoding elements and their association with developmental regulatory genes. Genome Biol 9:R34.

Flower DR. 1996. The lipocalin protein family: structure and function. Biochem J 318(pt 1):1-14. 
Goodman DS. 1981. Retinoid-binding proteins in plasma and in cells. Ann N Y Acad Sci 359:69-78.

Gray IC, Fallowfield J, Ford S, Nobile C, Volpi EV, Spurr NK. 1997. An integrated physical and genetic map spanning chromosome band 10q24. Genomics 43:85-88.

Halder G, Callaerts P, Gehring WJ. 1995. Induction of ectopic eyes by targeted expression of the eyeless gene in Drosophila. [see comments]. Science 267: 1788-1792.

Harland RM. 1991. In situ hybridization: an improved whole-mount method for Xenopus embryos. Methods Cell Biol 36:685-695.

Hitachi K, Danno H, Tazumi S, Aihara Y, Uchiyama H, Okabayashi K, Kondow A, Asashima M. 2009. The Xenopus Bowline/Ripply family proteins negatively regulate the transcriptional activity of T-box transcription factors. Int $\mathrm{J}$ Dev Biol 53:631-639.

Ho HY, Chang KH, Nichols J, Li M. 2009. Homeodomain protein Pitx3 maintains the mitotic activity of lens epithelial cells. Mech Dev 126:18-29.

Huang B, He W. 2010. Molecular characteristics of inherited congenital cataracts. Eur J Med Genet 53:347-357.

Hwang DY, Hong S, Jeong JW, Choi S, Kim H, Kim J, Kim KS. 2009. Vesicular monoamine transporter 2 and dopamine transporter are molecular targets of Pitx3 in the ventral midbrain dopamine neurons. J Neurochem 111:1202-1212.

Isaacs HV, Tannahill D, Slack JM. 1992. Expression of a novel FGF in the Xenopus embryo. A new candidate inducing factor for mesoderm formation and anteroposterior specification. Development 114:711-720.

Isaacs HV, Pownall ME, Slack JMW. 1994. eFGF regulates Xbra expression during Xenopus gastrulation. EMBO J 13:4469-4481.

Ishibashi S, Yasuda K. 2001. Distinct roles of maf genes during Xenopus lens development. Mech Dev 101:155-166.

Ito $\mathrm{T}$, Levenstein ME, Fyodorov DV, Kutach AK, Kobayashi R, Kadonaga JT. 1999. ACF consists of two subunits, Acf1 and ISWI, that function cooperatively in the ATP-dependent catalysis of chromatin assembly. Genes Dev 13: 1529-1539.

Jacobs FM, Smits SM, Noorlander CW, von Oerthel L, van der Linden AJ, Burbach JP, Smidt MP. 2007. Retinoic acid counteracts developmental defects in the substantia nigra caused by Pitx 3 deficiency. Development 134:2673-2684.

Jen WC, Gawantka V, Pollet N, Niehrs C, Kintner C. 1999. Periodic repression of Notch pathway genes governs the segmentation of Xenopus embryos. Genes Dev 13:1486-1499.

Jones MH, Hamana N, Nezu J, Shimane M. 2000a. A novel family of bromodomain genes. Genomics 63:40-45.

Jones MH, Hamana N, Shimane M. 2000b. Identification and characterization of BPTF, a novel bromodomain transcription factor. Genomics 63:35-39.
Kameda Y, Saitoh T, Fujimura T. 2011. Hes1 regulates the number and anterior-posterior patterning of mesencephalic dopaminergic neurons at the $\mathrm{mid} /$ hindbrain boundary (isthmus). Dev Biol 358:91-101.

Kawamura A, Koshida S, Takada S. 2008. Activator-to-repressor conversion of $\mathrm{T}$ box transcription factors by the Ripply family of Groucho/TLE-associated mediators. Mol Cell Biol 28:3236-3244.

Khosrowshahian F, Wolanski M, Chang WY, Fujiki K, Jacobs L, Crawford MJ. 2005. Lens and retina formation require expression of Pitx3 in Xenopus pre-lens ectoderm. Dev Dyn 234:577-589.

Kikuta H, Laplante M, Navratilova P, Komisarczuk AZ, Engstrom PG, Fredman D, Akalin A, Caccamo M, Sealy I, Howe K, Ghislain J, Pezeron G, Mourrain $P$, Ellingsen $S$, Oates $A C$, Thisse $C$, Thisse B, Foucher I, Adolf B, Geling A, Lenhard B, Becker TS. 2007. Genomic regulatory blocks encompass multiple neighboring genes and maintain conserved synteny in vertebrates. Genome Res 17:545-555.

Ladher R, Mohun TJ, Smith JC, Snape AM. 1996. Xom: a Xenopus homeobox gene that mediates the early effects of BMP-4. Development 122:2385-2394.

Lamonerie T, Trembley J, Lanctot C, Therrien M, Gautier Y, Drouin J. 1996. Ptx1, a bicoid-related homeo box transcription factor involved in the transcription of the pro-opiomelanocortin gene. Genes Dev 10:1284-1295.

Landis SC, Siegel RE, Schwab M. 1988. Evidence for neurotransmitter plasticity in vivo. II. Immunocytochemical studies of rat sweat gland innervation during development. Dev Biol 126:129-140.

Lebel M, Gauthier Y, Moreau A, Drouin J. 2001. Pitx3 activates mouse tyrosine hydroxylase promoter via a high-affinity binding site. J Neurochem 77:558-567.

Lombardo A, Slack JM. 2001. Abdominal B-type Hox gene expression in Xenopus laevis. Mech Dev 106:191-195.

Marchand R, Poirier LJ. 1983. Isthmic origin of neurons of the rat substantia nigra. Neuroscience 9:373-381.

Messmer K, Remington MP, Skidmore F, Fishman PS. 2007. Induction of tyrosine hydroxylase expression by the transcription factor Pitx3. Int J Dev Neurosci 25:29-37.

Mochizuki T, Karavanov AA, Curtiss PE, Ault KT, Sugimoto N, Watabe T, Shiokawa K, Jamrich M, Cho KW, Dawid IB, Taira M. 2000. Xlim-1 and LIM domain binding protein 1 cooperate with various transcription factors in the regulation of the goosecoid promoter. Dev Biol 224:470-485.

Münster D. 2005. Pitx3 und seine Rolle in der Augen- und Gehirnentwicklung. In: GSF-Forschungszentrum für Umwelt und Gesundheit Institut für Entwicklungsgenetik Neuherberg: Technischen Universität München. p 115.

Murato Y, Nagatomo K, Yamaguti M, Hashimoto C. 2007. Two alloalleles of Xenopus laevis hairy2 gene-evolution of duplicated gene function from a developmental perspective. Dev Genes Evol 217:665-673.

Nagy L, Saydak M, Shipley N, Lu S, Basilion JP, Yan ZH, Syka P, Chandraratna RA, Stein JP, Heyman RA, Davies PJ. 1996. Identification and characterization of a versatile retinoid response element (retinoic acid receptor response element-retinoid $\mathrm{X}$ receptor response element) in the mouse tissue transglutaminase gene promoter. J Biol Chem 271:4355-4365.

Nakamura H, Watanabe Y. 2005. Isthmus organizer and regionalization of the mesencephalon and metencephalon. Int J Dev Biol 49:231-235.

Napoli JL, Posch KP, Fiorella PD, Boerman MHEM. 1991. Physiological occurrence, biosynthesis and metabolism of retinoic acid: evidence for roles of cellular retinol-binding protein (CRBP) and cellular retinoic acid-binding protein (CRABP) in the pathway of retinoic acid homeostasis. Biomed Pharmacother 45:131-143.

Nieuwkoop PD, Faber J. 1967. Normal Table of Xenopus laevis (Daudin). Amsterdam: North Holland Press.

Ossipova O, Stick R, Pieler T. 2002. XSPR-1 and XSPR-2, novel Sp1 related zinc finger containing genes, are dynamically expressed during Xenopus embryogenesis. Mech Dev 115:117-122.

Pares X, Farres J, Kedishvili N, Duester G. 2008. Medium- and short-chain dehydrogenase/reductase gene and protein families: medium-chain and short-chain dehydrogenases/reductases in retinoid metabolism. Cell Mol Life Sci 65:3936-3949.

Pommereit D, Pieler T, Hollemann T. 2001. Xpitx3: a member of the Rieg/Pitx gene family expressed during pituitary and lens formation in Xenopus laevis. Mech Dev 102:255-257.

Reza HM, Ogino H, Yasuda K. 2002. LMaf, a downstream target of Pax6, is essential for chick lens development. Mech Dev 116:61-73.

Rieger DK, Reichenberger E, McLean W, Sidow A, Olsen BR. 2001. A double-deletion mutation in the pitx3 gene causes arrested lens development in aphakia mice. Genomics 72:61-72.

Sakazume S, Sorokina E, Iwamoto Y, Semina EV. 2007. Functional analysis of human mutations in homeodomain transcription factor PITX3. BMC Mol Biol 8:84.

Semina EV, Murray JC, Reiter R, Hrstka RF, Graw J. 2000. Deletion in the promoter region and altered expression of Pitx3 homeobox gene in aphakia mice. Hum Mol Genet 9:1575-1585.

Shawlot W, Behringer RR. 1995. Requirement for Lim 1 in head-organizer function. [see comments]. Nature 374:425-430.

Shi X, Bosenko DV, Zinkevich NS, Foley S, Hyde DR, Semina EV, Vihtelic TS. 2005. Zebrafish pitx3 is necessary for normal lens and retinal development. Mech Dev 122:513-527.

Shinga J, Itoh M, Shiokawa K, Taira S, Taira M. 2001. Early patterning of the 
prospective midbrain-hindbrain boundary by the HES-related gene XHR1 in Xenopus embryos. Mech Dev 109:225-239.

Shoji H, Nishi N, Hirashima M, Nakamura T. 2003. Characterization of the Xenopus galectin family. Three structurally different types as in mammals and regulated expression during embryogenesis. J Biol Chem 278:12285-12293.

Simon A, Hellman U, Wernstedt C, Eriksson U. 1995. The retinal pigment epithelial-specific 11-cis retinol dehydrogenase belongs to the family of short chain alcohol dehydrogenases. $J$ Biol Chem 270:1107-1112.

Simon A, Lagercrantz J, Bajalica-Lagercrantz S, Eriksson U. 1996. Primary structure of human 11-cis retinol dehydrogenase and organization and chromosomal localization of the corresponding gene. Genomics 36:424-430.

Smoczer C, Hooker L, Brode S, Wolanski M, KhosrowShahian F, Crawford M. (In Press). The Xenopus homeobox gene Pitx3 impinges upon somitogenesis and laterality. Biochem Cell Biol.

Sorokina EA, Muheisen S, Mlodik N, Semina EV. 2011. MIP/Aquaporin 0 rep- resents a direct transcriptional target of PITX3 in the developing lens. PLoS One 6:e21122.

Tada M, Casey ES, Fairclough L, Smith JC. 1998. Bix1, a direct target of Xenopus T-box genes, causes formation of ventral mesoderm and endoderm. Development 125:3997-4006.

Takada H, Hattori D, Kitayama A, Ueno N, Taira M. 2005. Identification of target genes for the Xenopus Hes-related protein XHR1, a prepattern factor specifying the midbrain-hindbrain boundary. Dev Biol 283:253-267.

Tanaka M, Murayama D, Nagashima M, Higashi T, Mawatari K, Matsukawa T, Kato S. 2007. Purpurin expression in the zebrafish retina during early development and after optic nerve lesion in adults. Brain Res 1153 $34-42$.

Trindade M, Tada M, Smith JC. 1999 DNA-binding specificity and embryological function of Xom (Xvent-2). Dev Biol 216:442-456

Tsuji S, Cho KW, Hashimoto C. 2003. Expression pattern of a basic helix-loophelix transcription factor Xhairy2b dur- ing Xenopus laevis development. Dev Genes Evol 213:407-411.

van den Munckhof P, Luk KC, Ste-Marie L, Montgomery J, Blanchet PJ, Sadikot AF, Drouin J. 2003. Pitx3 is required for motor activity and for survival of a subset of midbrain dopaminergic neurons. Development 130: 2535-2542.

Varnum DS, Stevens LC. 1968. Aphakia, a new mutation in the mouse. J Hered 59:147-150.

Wald G. 1968. The molecular basis of visual excitation. Nature 219:800-807.

Wolda SL, Moon RT. 1992. Cloning and developmental expression in Xenopus laevis of seven additional members of the Wnt family. Oncogene 7: 1941-1947.

Würst W, Auerbach AB, Joyner AL. 1994. Multiple developmental defects in Engrailed-1 mutant mice: an early midhindbrain deletion and patterning defects in forlimbs and sternum. Developement 120:2065-2075.

Zeng L, Zhou MM. 2002. Bromodomain: an acetyl-lysine binding domain. FEBS Lett 513:124-128. 